\title{
Modelling of sea salt concentrations over Europe: key uncertainties and comparison with observations
}

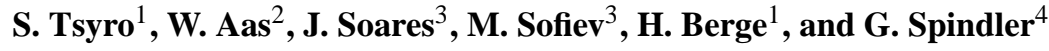 \\ ${ }^{1}$ Norwegian Meteorological Institute, P.O. Box 43, Blindern, 0313, Oslo, Norway \\ ${ }^{2}$ Norwegian Institute for Air Research, P.O. Box 100, 2027, Kjeller, Norway \\ ${ }^{3}$ Finnish Meteorological Institute, P.O. Box 503, 00101, Helsinki, Finland \\ ${ }^{4}$ Leibniz Institute for Tropospheric Research, Permoserstraße 15, 04318, Leipzig, Germany \\ Received: 4 March 2011 - Published in Atmos. Chem. Phys. Discuss.: 11 April 2011 \\ Revised: 23 September 2011 - Accepted: 28 September 2011 - Published: 18 October 2011
}

\begin{abstract}
Sea salt aerosol can significantly affect the air quality. Sea salt can cause enhanced concentrations of particulate matter and change particle chemical composition, in particular in coastal areas, and therefore should be accounted for in air quality modelling. We have used an EMEP Unified model to calculate sea salt concentrations and depositions over Europe, focusing on studying the effects of uncertainties in sea salt production and lifetime on calculation results. Model calculations of sea salt have been compared with EMEP observations of sodium concentrations in air and precipitation for a four year period, from 2004 to 2007, including size (fine/coarse) resolved EMEP intensive measurements in 2006 and 2007. In the presented calculations, sodium air concentrations are between $8 \%$ and $46 \%$ overestimated, whereas concentrations in precipitation are systematically underestimated by $65-70 \%$ for years 2004 2007. A series of model tests have been performed to investigate the reasons for this underestimation, but further studies are needed. The model is found to reproduce the spatial distribution of $\mathrm{Na}^{+}$in air and precipitation over Europe fairly well, and to capture most of sea salt episodes. The paper presents the main findings from a series of tests in which we compare several different sea spray source functions and also look at the effects of meteorological input and the efficiency of removal processes on calculated sea salt concentrations. Finally, sea salt calculations with the EMEP model have been compared with results from the SILAM model and observations for 2007. While the models produce quite close results for $\mathrm{Na}^{+}$at the majority of 26 measurement sites, discrepancies in terms of bias and temporal correlation are also found.
\end{abstract}

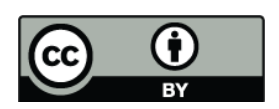

Correspondence to: S. Tsyro (svetlana.tsyro@met.no )
Those differences are believed to occur due to differences in the representation of source function and size distribution of sea salt aerosol, different meteorology used for model runs and the different models' resolution. This study contributes to getting a better insight on uncertainties associated with sea salt calculations and thus facilitates further improvement of aerosol modelling on both regional and global scales.

\section{Introduction}

Sea salt is a dominant aerosol type over oceans, also contributing significantly to the global aerosol burden. Sea salt aerosol plays an important role in atmospheric chemistry, providing the surface for heterogeneous reactions and acting as a sink for anthropogenic and natural gaseous tracers, e.g. for nitric and sulphuric acids. For example, the presence of sea salt aerosols in the atmosphere was shown to significantly alter the regional distribution of other inorganic aerosols, namely sulphate, nitrate and ammonium (van den Berg et al., 2000; Liu et al., 2006). Furthermore, sea salt is an important source of base cations, which reduce the acidity of air and precipitation and increase soil base saturation. Thus, the deposition of base cations can partly counteract soil acidification and contribute to the recovery of ecosystems (van Loon et al., 2005).

With regard to air pollution issue, sea salt is a ubiquitous constituent of particulate matter (PM) and can significantly affect the air quality in coastal areas. Studies of the impact of sea spray on PM concentrations in coastal areas show that sea spray both enhances the levels and changes the chemical composition of PM (e.g. Pryor et al., 2007; Athanasopoulou et al., 2008). Sea salt contributes to the concentrations of

Published by Copernicus Publications on behalf of the European Geosciences Union. 
$\mathrm{PM}_{10}$ and $\mathrm{PM}_{2.5}$, current air quality metrics, thus it has to be accounted for in air quality modelling in order to achieve a mass closure of PM and to provide accurate assessments of PM levels. In the European Commission's Air Quality directive (EC DIRECTIVE 2008/50/EC, 2008) it is stated that exceedences of PM can be corrected for contributions from natural sources if these can be determined with sufficient certainty. Since sea salt contributions can hardly (or not always) be determined from air quality measurements alone, model calculations can be used for this purpose, which requires a good confidence in model performance. Pryor et al. (2007) demonstrate that including sea spray in the model affects calculated composition and size distribution of PM and conclude that it is important to account for heterogeneous reactions on sea salt when evaluating the potential emission reduction measures to reduce PM in coastal cities. Model calculations in Athanasopoulou et al. (2008) suggest that an enhanced nitrate formation takes place on sea salt particles over and downwind the shipping lanes in the Aegean Sea. The nitrate is then transported to the land and contributes to PM pollution in Athens.

The generation of sea spray is commonly described with so-called source functions. Some of the proposed source functions are based on field measurements (e.g. Smith et al., 1993; O'Dowd et al., 1997; Andreas, 1998; Smith and Harrison, 1998; Vignati et al., 2001; De Leeuw et al., 2000), others on laboratory data (e.g. Monahan et al., 1986; Mårtensson et al., 2003), or on both (e.g. Gong, 2003). In regional and global chemical transport models, the source functions by Mårtensson et al. (2003), Monahan et al. (1986) and Gong (2003) are broadly used to calculate bubble-mediated sea spray production, whereas the schemes by Smith et al. (1993) and Smith and Harrison (1998) are used to calculate spume sea spray production. Comparative reviews of different source functions reveal that estimated sea spray fluxes vary by several orders of magnitude for different size ranges and wind speeds (Andreas, 1998; Guelle et al., 2001; Vignati et al., 2001; and Gong, 2003). Even source functions employing the same "white-cap method" differ by about a factor of 7 (Lewis and Schwartz, 2004). Given the uncertainties associated with calculating sea spray generation, an accurate reproduction of sea salt concentrations with chemical transport models is quite a challenging task.

In this work, we study the ability of the EMEP model to reproduce observed levels and distribution of sea salt on a European scale for multiple years. First, we give a short overview of sea spray source functions and examine the behaviour of selected source functions using a box-model. Then, the sea salt parameterisation scheme presently implemented in the Unified EMEP model is described and calculation results are presented. The performance of the EMEP model for sea salt (i.e. sodium concentrations in air and in precipitation) is evaluated with observations for years from 2004 to 2007 . A sensitivity analysis is performed to investigate the effect of modelling uncertainties on calculated sea salt concentrations, as compared to measurements. We also compare sea salt concentrations, calculated with the EMEP model employing different source functions, and evaluate the model results against observations. Finally, sea salt calculations with the EMEP model are compared with those from SILAM model of the Finnish Meteorological Institute. Compared with several earlier publications (e.g. Gong et al., 1997, 2002, 2003; Guelle et al., 2001; Grini et al., 2002; Foltesu et al., 2004), this work includes a comparative study of several sea spray source functions and presents multi-year sea salt calculations. The assessment of the model performance is based on a more extensive than earlier amount of observational data, and a sensitivity analysis of calculated sea salt to the uncertainties in process formulations and input parameters is provided.

\section{Notes on current status of sea salt modelling}

Sea salt aerosols originate from sea spray droplets. The generation of sea spray occurs as the waves break on the surface of the ocean and whitecaps form causing the entrainment of air in the water. On the open ocean, this process is driven by the surface wind, whereas in the surface zone the wave breaking is largely due to their interaction with the sea bottom surface, which intensifies the whitecap formation (de Leeuw et al., 2000). Two main mechanisms responsible for sea spray formation are the air bubble bursting during whitecap formation and the direct tearing of droplets from the tops of breaking waves. The bubble-mediated mechanism produces sea spray droplets with radii ranging mostly between 0.25 and $8 \mu \mathrm{m}$ (Guelle et al., 2001), whereas spume droplets are typically larger than $10-20 \mu \mathrm{m}$. Note that we refer to the radii of sea salt aerosol at a relative humidity of $80 \%\left(r_{80}\right)$ throughout the paper, unless different is specified (Andreas et al., 2001).

A size dependent source function describes the number of droplets of a given size produced at the sea surface per unit surface area per unit time as a function of the surface forcing (i.e. wind speed, wave breaking, surface stress, etc.). Comprehensive overviews of sea spray functions can be found in Andreas (1998) and Schulz et al. (2004). Among sea spray source functions broadly used in regional and global transport models are those developed by Monahan et al. (1986), Smith et al. (1993), Smith and Harrison (1998), Andreas (1998), Vignati et al. (2001), Gong (2003), Mårtensson et al. (2003) and Clarke et al. (2006).

The limitation of all current formulations of source function is due to their attempt to express the flux in terms of the current wind speed as the only variable (Hoppel et al., 2002). Only scheme by Mårtensson et al. (2003) includes dependence on the surface temperature and allows the possibility of accounting for water salinity (Sofiev et al., 2011). In reality, flux intensity and size distribution of sea spray also depends on other variables, i.e. history of wind velocity, 

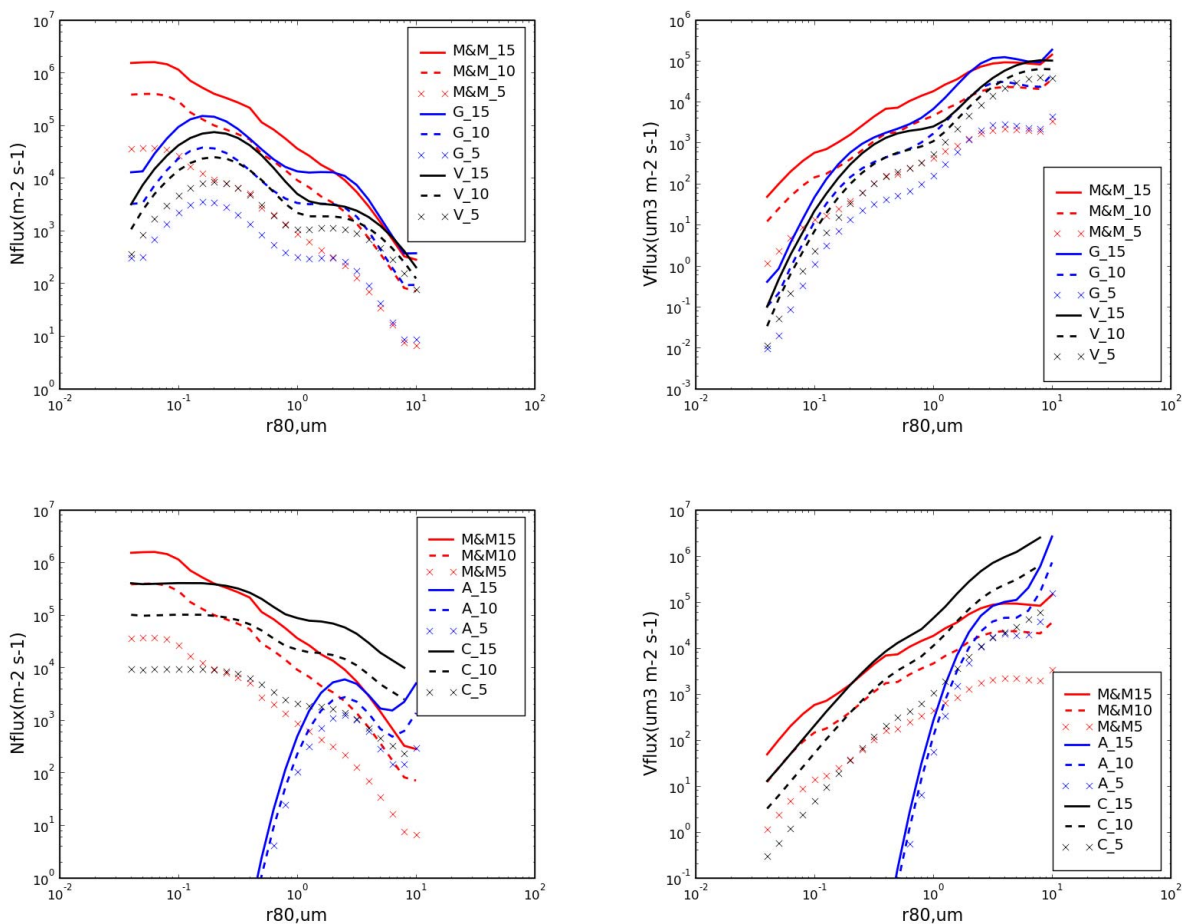

Fig. 1. Sea spray flux as a function of droplet radius at $80 \%$ relative humidity calculated with the M\& M source functions are compared to those from V01 and G03 (upper panel), A98 and C06 (lower panel) for wind speeds of 5, 10 and $15 \mathrm{~m} \mathrm{~s}^{-1}$ : sea spray number (left) and volume (right).

wave breaking characteristics, fetch, sea water temperature and salinity, occurrence of organics films, the thermal stability of the atmospheric and ocean surface layer. Therefore it cannot be expected that a single universal sea spray source function can be formulated in terms of only few parameters (de Leeuw et al., 2003).

A number of comparative studies conclude that the formulation of sea salt generation by Monahan et al. (1986) gives the soundest results for bubble-mediated sea spray, as they best match with both observations and other source functions (Guelle et al., 2001; De Leeuw et al., 2000; Andreas, 1998). Vignati et al. (2001) found an excellent agreement between Monahan et al. (1986) scheme and measurements reported in O'Dowd et al. (1997) for the number size distribution of sea salt aerosols down to dry diameters of $0.4 \mu \mathrm{m}$. However, extrapolation of Monahan et al. (1986) source function to smaller sizes resulted in too great production of the number of smallest droplets (Vignati et al., 2001; Mårtensson et al., 2003). Also Gong (2003) concluded that Monahan et al. (1986) source function gave fairly good results for total sea salt mass and its wind dependence for sea salt aerosols larger than $0.4 \mu \mathrm{m}$ dry diameter. For sub-micron sea salt aerosol, a source function from Mårtensson et al. (2003), covering aerosols with dry diameters between 0.02 and $2.8 \mu \mathrm{m}$, was shown to give good results (Mårtensson, 2007; Nilsson et al., 2007).
Pierce and Adams (2006) found that sea-salt mass concentrations from both Monahan et al. (1986) and Mårtensson et al. (2003) parameterisations were much lower compared to those from O'Dowd et al. (1997) and Clarke et al. (2006) functions. This is because the first two parameterisations predicted lower emissions in super-micron sizes compared to the latter ones. Besides, there is no production of sea salt particles larger than $2.8 \mu \mathrm{m}$ on Mårtensson et al. (2003) (see Fig. 1). However, taking into account the negative bias in wind speeds in their model, Pierce and Adams (2006) anticipated that model runs with O'Dowd et al. (1997) and Clarke et al. (2006) parameterisations were likely to over-predict the sea-salt concentrations in many locations. Results presented in Ma et al. (2008) also indicate that Clarke et al. (2006) parameterisation tends to predict too large burden of sea salt. All in all, given the uncertainties in model meteorology, treatment of aerosol processing and in observational data, Pierce and Adams (2006) found it difficult to say definitively which parameterisation was the best.

Evaluations of sea salt calculations with regional and global models show rather variable results. Most of the climate and global transport models have to date compared calculated monthly averaged sea salt $\left(\mathrm{Na}^{+}\right)$concentrations with observations (e.g. Gong et al., 1997b, 2002; Grini et al., 2002; Ma et al., 2008). Though most of model results lied on average within a factor-of-two range of observations, both significant over- and underestimations were reported for 
individual sites. For instance, Stier et al. (2005) found that calculated with ECHAM5, sea salt concentrations agreed within a factor of 2 with observations at remote marine sites, whereas they overestimated IMPROVE and GAW measurements by a factor of 2 to 10 , especially for small concentrations. Using Monahan et al. (1986) within a global TM3 model, Guelle et al. (2001) found a fair agreement between calculated and measured monthly sea salt air concentrations (some underestimation in January-March for marine sites on Iceland and Ireland). For sea salt in precipitation, the model underestimated observations for most of the sites except the coastal ones, and by as much as an order of magnitude at sites away from the coast. Furthermore, making use of Monahan et al. (1986) source function, FIZ-C climate model overestimated $\mathrm{Na}^{+}$in air by $20-75 \%$ (Gong et al., 1997b), and GCMIII climate model underestimated $\mathrm{Na}^{+}$in air by up to a factor of 2 (Gong et al., 2002).

Using a combination of Monahan et al. (1986) and Mårtinsson et al. (2003) parameterisations, the regional model MATCH was found to severely overestimate $\mathrm{Na}^{+}$ in air at Norwegian and Danish sites, whereas it underestimated only slightly for Dutch sites (Foltescu et al., 2004). $\mathrm{Na}^{+}$in precipitation was underestimated by about $40 \%$ by MATCH. Also the regional climate model RegCM, using a modified Monahan et al. (1986) function, overestimated sea salt in air by between 30 and as much as $300 \%$ (Zakey et al., 2008). Calculations from the regional climate/chemistry model REMOTE with sea salt parameterisation from Geever et al. (2005) produced $\mathrm{Na}^{+}$air concentration 2 to 6 times higher than observed (Langmann et al., 2008). Calculated $\mathrm{Cl}^{-}$concentrations in precipitation were underestimated in January, while overestimated in June compared to measurements.

\section{The EMEP model}

\subsection{General description}

The full description of the EMEP chemical transport model is given in Simpson et al. (2003), Fagerli et al. (2004), Tsyro (2008), and can also be found on EMEP website http://www.emep.int. The model calculation domain covers the whole of Europe, and also includes a large part of the North Atlantic and Arctic areas. In vertical direction, the model is resolved with 20 layers, reaching a height of ca. $100 \mathrm{hPa}$. The lowest model layer is approximately $90 \mathrm{~m}$ thick. In the present calculations, the horizontal resolution of approximately $50 \times 50 \mathrm{~km}^{2}$ was used. Meteorological model HIRLAM was used to drive most of presented simulations. Note that calculations prior to the year 2007 were made using meteorological fields, calculated with an older version of HIRLAM weather prediction model (called PARLAM-PS), while for 2007, an updated version of HIRLAM (version 7.1) was used. PARLAM-PS was run with $50 \times 50 \mathrm{~km}^{2}$ res- olution on a polar-stereographic projection, while HIRLAM was run on $0.2 \times 0.2^{\circ}$ rotated spherical grid and the meteorological fields were then interpolated to the EMEP polarstereographic projection. In addition to PARLAM-PS and HIRLAM v.7.1, meteorology from ECMWF-IFS (Integrated Forecast System) for 2006 was used in sensitivity tests. The ECMWF-IFS meteorological fields were retrieved on a geographical grid with $0.2 \times 0.2^{\circ}$ resolution. More in-depth study of the effect of using different meteorological drivers on EMEP model results, including verification of meteorological data, are documented in Tsyro et al. (2010).

The EMEP model describes the emissions, chemical transformations, transport and dry and wet removal of gaseous and aerosol components. The standard model version distinguishes between two size fractions for aerosols, i.e. fine aerosol $\left(\mathrm{PM}_{2.5}\right)$ and coarse aerosol $\left(\mathrm{PM}_{2.5-10}\right)$. Dry deposition parameterisation for aerosols follows standard resistance-formulations, accounting for diffusion, impaction, interception, and sedimentation. Meteorology and land-use dependent dry deposition velocities are calculated for the two aerosol sizes, taking into account particle hygroscopic growth. Wet scavenging is treated with simple scavenging ratios, accounting for in-cloud and sub-cloud processes. The scavenging ratios are assigned to crudely reflect the solubility of different aerosol components, and the size differentiated collection efficiencies are used in sub-cloud aerosol washout.

\subsection{Parameterisation of sea salt production}

The Unified EMEP model is primarily designed to calculate regional concentrations of $\mathrm{PM}_{2.5}$ and $\mathrm{PM}_{10}$. Hence, standard model runs include sea salt particles with ambient diameters up to about $10 \mu \mathrm{m}$, which mainly originate from the bubblemediated sea spray.

The parameterisation scheme for calculating sea salt generation in the EMEP model makes use of two source functions for bubble-mediated sea spray production. The first one is a source function from Monahan et al. (1986), based on results from Monahan and O'Muircheartaigh (1980):

$\frac{d F}{d r_{80}}=1.373 \times U_{10}^{3.41} \times r_{80}^{-3}\left(1+0.057 r_{80}^{1.05}\right) \times 10^{1.19 \exp \left(-B^{2}\right)}$

where $d F / d r_{80}$ is the rate of sea salt droplet generation per unit area of sea surface and per increment of droplet actual ("wet") radius, $r_{80}$ is the aerosol radius at $80 \%$ relative humidity, $U_{10}$ is the wind speed at $10 \mathrm{~m}$, and $B=(0.380$ $\log \left(r_{80)}\right) / 0.650$.

The second one is a source function from the work of Mårtensson et al. (2003), which is formulated for a salinity of $33 \%$ :

$\frac{d F}{d \log d_{\mathrm{d}}}=3.84 \times 10^{-6} A_{\mathrm{w}} T_{\mathrm{w}}+B_{k} \times U_{10}^{3.41}$

where $d F / d\left(\log d_{\mathrm{d}}\right)$ is the flux of sea salt aerosols per unit area of the whitecap cover and per increment of $\left(\log d_{\mathrm{d}}\right), d_{\mathrm{d}}$ 
Table 1. Size fractions used for calculations of sea spray production in the EMEP model: shown are the borders for dry diameters $\left(d_{\mathrm{dry}}\right.$ in $\mu \mathrm{m}$ ).

\begin{tabular}{llllllllllllll}
\hline$d_{\text {dry }}$ & 0.02 & 0.05 & 0.10 & $0.145^{*}$ & 0.25 & $0.419^{*}$ & 0.60 & 1.25 & 1.6 & 3.0 & 5.0 & 10 & 17 \\
\hline & & & & & & &
\end{tabular}

* Chosen in order to comply with formula from Mårtensson et al. (2003).

Here, light-grey and black colours mark the fine and the coarse sea salt aerosols, which are included in standard calculations; the size fractions in grey boxes have been used for test runs.

is the dry diameter, $T_{\mathrm{w}}$ is the temperature of sea water, and $A_{k}$ and $B_{k}$ are the parameters describing the dependence of sea salt flux on the aerosol size:

$A_{k}=C_{4} d_{\mathrm{d}}^{4}+C_{3} d_{\mathrm{d}}^{3}+C_{2} D_{\mathrm{d}}^{2}+C_{1} d_{\mathrm{d}}+C_{0}$

$B_{k}=D_{4} d_{\mathrm{d}}^{4}+D_{3} d_{\mathrm{d}}^{3}+D_{2} d_{d}^{2}+D_{1} D_{\mathrm{d}}+D_{0}$

The empirical coefficients $C_{i}$ and $D_{i}$ are tabulated according to Mårtensson et al. (2003).

In the EMEP model, the sea salt fluxes are calculated for particle dry diameters ranging from 0.02 to $6 \mu \mathrm{m}$, with a possibility to extend to larger sizes. The size range is divided onto size bins as shown in Table 1, and Mårtensson et al. (2003) parameterisation is applied for first six bins, while Monahan et al. (1986) parameterisation is used for the rest. Then, the total production rates of fine and coarse sea salt are found by integrating the size resolved fluxes over respective size intervals.

The relationship between the dry radius $r_{\mathrm{d}}$ and $r_{80}$ of sea salt aerosols is expressed through an empirical formula of Gerber (1985), as suggested in Gong et al. (1997a):

$r_{\mathrm{w}}=\left[\frac{0.7674 r_{\mathrm{d}}^{3.079}}{2.573 \times 10^{-11} r_{\mathrm{d}}^{-1.424}-\log S}+r_{\mathrm{d}}^{3}\right]^{1 / 3}$

The wind speed at the height $z_{10}=10 \mathrm{~m}$ is either taken directly from the NWP model, if available, or calculated within the EMEP model as

$U_{10}=U_{\text {ref }} \frac{\ln \left(\frac{z}{z}\right)-\psi\left(\frac{z_{10}}{L}\right)+\psi\left(\frac{z_{10}}{L}\right)}{\ln \left(\frac{z}{z}\right)-\psi\left(\frac{z_{\text {ref }}}{L}\right)+\psi\left(\frac{z_{\text {ref }}}{L}\right)}$

In (3) and (4), $S$ is the saturation ratio, $U_{\text {ref }}$ is the wind speed at the model lowest level $z_{\text {ref }}$ (about $45 \mathrm{~m}$ ), $\Psi$ is the similarity function for momentum (Simpson et al., 2003). The roughness parameter $z_{0}$ is calculated using Charnock's relation (Stull, 1988; Garratt, 1992) as

$z_{0}=\beta \times u_{*}^{2} / g$

where $u_{*}$ is the friction velocity, $g$ is the gravitational acceleration, and $\beta$ is the empirical constant. In the present version of the EMEP model $\beta=0.0114$ is adopted.

In the model, generated sea salt aerosols are assumed to be instantaneously mixed within the model lowest layer (approximately $90 \mathrm{~m}$ height) at each time step. The transport and removal of sea salt is described individually for the fine and coarse fractions in the EMEP model.

\section{Measurements}

Measurement data used in this work are primarily the concentrations of sodium $\left(\mathrm{Na}^{+}\right)$in air and precipitation in the years 2004 to 2007 from EMEP monitoring network. The list of stations and their details are provided in Table A1 in the Appendix. In addition, data obtained during two EMEP intensive measurement periods in June 2006 and January 2007 have been used.

In the regular EMEP measurements of sodium air concentrations, aerosols are commonly sampled at a standard height of $2 \mathrm{~m}$, using a filter pack sampler, with a daily sampling frequency following recommendations from the EMEP Manual for sampling and chemical analysis (EMEP, 1995). This sampler has no defined cut off, but it normally captures particles about $\mathrm{PM}_{10}$ size, depending on the flow rate. Teflon aerosol filters are usually employed and the analytical method for sample analysis is mainly ion chromatography. No information concerning the amount of sea salt particles larger than $10 \mu \mathrm{m}$ captured on the filter pack sampler has not been available. The only estimate was made for Birkenes where simultaneous measurements were performed with filter pack and low-volume sampler. These data indicated that in $\mathrm{Na}^{+}$ measured with filter pack, the fraction of $\mathrm{Na}^{+}$smaller than $10 \mu \mathrm{m}$ comprised $90 \%$ in June 2006 and $87 \%$ in January 2007 (Wenche Aas, NILU, personal communication, 2011). Concentrations in precipitation are commonly sampled using a "wet-only" sampler, which is the recommended method in EMEP. However, there are a few countries using bulk collectors. Details of sampling and analytical methods can be found in Hjellbrekke and Fjæraa (2009). The quality of the analytical performance is checked annually in the EMEP lab inter-comparison (e.g. Uggerud, 2009) and the standard deviation is generally around $5 \%$.

In the intensive measurement periods, low volume samplers equipped with quartz filters were typically used to collect $\mathrm{PM}_{10}$ and $\mathrm{PM}_{2.5}\left(\right.$ or $\left.\mathrm{PM}_{1}\right)$. The $\mathrm{PM}$ samples were then used for weighing and subsequent chemical analyses.

The predominant source of sodium is ocean and sea water, though there are some anthropogenic sources that may contribute to sodium concentrations to some extent. For instance, Maykut et al. (2003) identified craft pulp mills as a possible source of sodium in Seattle. Furthermore, salting of icy roads may be an important source in areas with winter 
climate, but a study for Stockholm by Blomqvist and Johansson (1999) showed that ninety per cent of the total salt deposition occurs within $20 \mathrm{~m}$ from the road.

The size distribution of sea salt mass in marine air shows mainly one peak in the coarse particle range (Sellegri et al., 2001), whereas it may have different size distribution in inland air. A study by Ookii et al. (2002) in Japan showed bimodal peaks in the fine and coarse particle range. They stated that in urban areas in Japan incineration plants account for a large fraction of the total sodium emission, and the average concentration of fine sodium in urban air was three times higher than that in marine air. In Europe, anthropogenic emissions of sodium are reported from various combustion and industrial processes, with highest percentage contribution coming from glass production (Hellsten et al., 2007). Combustion of lignite for domestic heating is one of the main anthropogenic sources of sodium in Germany (G. Spindler, personal communication, 2011). Van Loon et al. (2005) estimated that anthropogenic emission of sodium contributes with $1.1 \%$ of the coarse primary PM, $0.7 \%$ of the fine PM. The $\mathrm{Na} / \mathrm{Cl}$ mass relationship of 1.8 , as in sea water (Millero, 2004; Warren, 2009), could be an indicator of whether the salt is mainly from sea salt, though the anthropogenic sodium that is emitted as $\mathrm{NaCl}$ is often difficult to distinguish from sea-salt $\mathrm{NaCl}$. Furthermore, chloride depletion due to evaporation of $\mathrm{HCl}$ alters the $\mathrm{Na} / \mathrm{Cl}$ ratio (White, 2008).

\section{Results from sea salt calculations}

\subsection{Comparative study within box-model}

Comparison of sea salt production calculated with selected source functions has been made using a box-model. Learning about the differences between scheme calculations with respect to size distribution and wind speed dependence of sea salt flux will facilitate our interpretation of sea salt calculated with the EMEP model.

We have compared the following source functions: a combined Mårtensson et al. (2003) and Monahan et al. (1986), Vignati et al. (2001), Gong (2003), Clarke et al. (2006), and Andreas (1998) (referred to as M \& M, V01, G03, C06 and A98 respectively). The comparison has been limited to bubble-mediated sea spray droplets with radii $r_{80}$ up to about $10 \mu \mathrm{m}$. The same discretisation of the spray size range has been applied in calculations with all considered source functions.

Figure 1 shows the size dependence of sea spray fluxes calculated with M \& M, G03, V01, C06 and A98 source functions for wind speeds of 5,10 and $15 \mathrm{~m} \mathrm{~s}^{-1}$ (note that the results are presented in two graphs for transparency sake). Shown are the fluxes of sea spray particle number (left picture) and volume (right picture). Pronounced differences are seen between the sea spray fluxes from different source func- tions and their dependencies on wind speed, with respect to both the intensity and the size distribution of sea spray droplets. In summary, the comparison study between the selected source functions shows that:

- M\& M number and volume fluxes of spray are larger than those from G03 and V01 for droplets smaller than about $2 \mu \mathrm{m}$. For the same wind speed, M \& M calculates fewer droplets smaller than $0.1 \mu \mathrm{m}$, but more droplets larger than $0.2 \mu \mathrm{m}$ from sea water at $20^{\circ} \mathrm{C}$ compared to $10^{\circ} \mathrm{C}$ (not shown);

- the largest discrepancies in sea spray fluxes (up to two orders of magnitude) are found for droplets with $r_{80}$ smaller than $0.1 \mu \mathrm{m}$. Sea spray fluxes with droplets in this size range contribute greatly to the sea salt particle number, but negligibly to the mass;

- M\&M and G03 fluxes are quite close for all wind speeds for sea spray droplets larger than about $0.4 \mu \mathrm{m}$. This is not too surprising since G03 was derived based on Monahan et al. (1986) formula;

- stronger wind dependence of sea spray fluxes is apparent for G03 and M \& M source functions compared to V01. Particularly pronounced are differences for lower winds (e.g. $5 \mathrm{~m} \mathrm{~s}^{-1}$ ), where sea spray fluxes from V01 are much larger than those from M \& M and G03 schemes;

- C06 shows wind dependence of sea spray flux similar to that from $\mathrm{M} \& \mathrm{M}$, while the size distribution of sea spray droplets from those schemes are different, namely C06 calculates smaller fluxes of sea salt aerosols below $r_{80}$ of $0.2 \mu \mathrm{m}$, but larger fluxes for larger droplets as compared to $\mathrm{M} \& \mathrm{M}$.

- A98 fluxes differ significantly from the other source functions as it is limited to sea spray droplets with $r_{80}$ larger than $1 \mu \mathrm{m}$.

\subsection{Calculations with the EMEP model}

The combined source function M \& M based on Mårtensson et al. (2003) and Monahan et al. (1986) is used to calculate sea salt aerosol production within the Unified EMEP model, version rv3.1 (Simpson et al., 2003; Tsyro, 2008). Results of comparison of model calculated sea salt concentrations with observations are documented in EMEP reports (e.g. EMEP Reports 4/2006, 4/2007, 4/2008 and 4/2009 at http://www. emep.int).

Annual mean concentrations of sea salt in 2006, calculated with the EMEP model using different source function, are presented in Fig. 2. Sea salt particles up to approximately $10 \mu \mathrm{m}$ in diameter at the ambient relative conditions are accounted for. The largest sea salt concentrations are produced by $\mathrm{C} 06$ source function, which is consistent with 
Table 2. Comparison statistics between calculated and observed $\mathrm{Na}^{+}$concentrations in air and precipitation and $\mathrm{Na}^{+}$wet deposition.

\begin{tabular}{|c|c|c|c|c|}
\hline & 2004 & 2005 & 2006 & $2007 *$ \\
\hline \multicolumn{5}{|c|}{$\mathrm{Na}^{+}$air } \\
\hline$N_{\text {sites }}$ & 11 & 17 & 22 & 26 \\
\hline Bias (\%) & 46 & 22 & 12 & 8 \\
\hline$R$ & 0.78 & 0.81 & 0.79 & 0.76 \\
\hline RMSE & 0.39 & 0.56 & 0.61 & 0.65 \\
\hline \multicolumn{5}{|c|}{$\mathrm{Na}^{+}$precip } \\
\hline$N_{\text {sites }}$ & 31 & 32 & 38 & 40 \\
\hline Bias (\%) & -63 & -66 & -64 & -73 \\
\hline$R$ & 0.73 & 0.70 & 0.93 & 0.77 \\
\hline RMSE & 1.62 & 1.67 & 0.65 & 2.98 \\
\hline \multicolumn{5}{|c|}{$\mathrm{Na}^{+}$w. dep } \\
\hline Bias (\%) & -69 & -76 & -77 & -72 \\
\hline$R$ & 0.87 & 0.92 & 0.71 & 0.89 \\
\hline
\end{tabular}

* Note that HIRLAM 7.1 version was used for 2007 model calculations, while meteorology for 2004-2006 is based on PARLAM-PS.

results of calculations in Pierce and Adams (2006) and Ma et al. (2008). Somewhat lower sea salt levels are calculated using V01, while the lowest sea salt concentrations are calculated with SH98 parameterisation. The sea salt concentrations from G03 are quite close to the EMEP standard results, whereas sea salt concentrations from A98 are somewhat lower.

Figure 3 displays two vertical cross-sections of sea salt for geographical locations shown in the small maps. The enhanced sea salt concentrations associated with emission areas are pronounced up to about $600-700 \mathrm{~m}$. The concentrations drop by about an order of magnitude at $1 \mathrm{~km}$ height, where sea salt is still present at concentration levels of $1-2 \mu \mathrm{g} \mathrm{m}^{-3}$. At $2-3 \mathrm{~km}$ heights, sea salt concentrations are about two orders of magnitude smaller than in the surface layer. Further up, sea salt is present at very low concentrations and shows quite uniform horizontal distribution.

\section{Comparison with measurements}

For evaluation of model calculations of sea salt, they have been compared with observational data described in Sect. 4. From the model, $\mathrm{Na}^{+}$concentrations have been derived as $34 \%$ of the calculated sea salt mass. For comparison with observations, $\mathrm{Na}^{+}$concentrations at $2 \mathrm{~m}$ height have been from the concentrations at the model's lowest layer (appr. $45 \mathrm{~m}$ ) applying correction factors based on an assumption about constant turbulent fluxes in the surface layer. In this section, results for standard model calculations, i.e. using M \& M parameterisation, are shown, while results for cal- culations using the other parameterisations are presented in the following section.

\subsection{Comparison with EMEP monitoring data}

Table 2 summarises the results of annual statistical analysis of model calculated versus measured $\mathrm{Na}^{+}$concentrations in air and precipitation for years 2004 to 2007.

The model overestimates measured $\mathrm{Na}^{+}$air concentrations in all years, but the overestimation decreases from $46 \%$ in 2004 to $8 \%$ in 2007. One of the reasons for the decrease of model's positive bias is a gradual increase in the number of stations with $\mathrm{Na}^{+}$measurements in central Europe between 2004 and 2007, for which the model shows a tendency to underestimate $\mathrm{Na}^{+}$. In addition, changes in model results for 2007 are also due to the use of a new meteorological driver, namely an updated version of the HIRLAM model. It was shown in Tsyro et al. (2010) that due to more intensive upward turbulence mixing and more precipitation in HIRLAM meteorology, the EMEP model calculates surface concentrations of all aerosols somewhat lower compared to calculations driven by PARLAM-PS meteorology.

For sites, at which $\mathrm{Na}^{+}$air concentrations were measured in all years between 2004 and 2007, the model bias varies from $36 \%$ in 2004 to $26 \%$ in 2005 and to $35 \%$ in 2006 . Again, it decreases to $15 \%$ in 2007 partly due to changing the meteorological model. The fairly good correlation (also shown in Table 2) between calculated and observed annual mean $\mathrm{Na}^{+}$concentrations indicates that the model realistically describes the geographical distribution of sea salt over Europe. For $\mathrm{Na}^{+}$in air, the spatial correlation coefficients lie between 0.76 and 0.81 , while for $\mathrm{Na}^{+}$in precipitation they range between 0.70 and 0.93 in the considered period.

The frequency distribution of modelled $\mathrm{Na}^{+}$air concentrations in 2006 is very close to the observed one for values below about $7 \mu \mathrm{g} \mathrm{m}^{-3}$ (Figure 4 , left panel). The model somewhat under-predicts the number of days with enhanced concentrations of 7.5-9.5 $\mu \mathrm{g} \mathrm{m}^{-3}$ and does not predict a relatively few occurrences of sea salt episodes with $\mathrm{Na}^{+}$above $12 \mu \mathrm{g} \mathrm{m}^{-3}$.

Measurements of $\mathrm{Na}^{+}$concentrations in precipitation are available at a larger number of EMEP stations compared to $\mathrm{Na}^{+}$air concentration data, in particular at more in-land sites. Contrary to $\mathrm{Na}^{+}$air concentrations, the model underestimates $\mathrm{Na}^{+}$concentrations in precipitation by between $63 \%$ and $73 \%$ for the years 2004-2007. At the same time, the calculated precipitation is only slightly biased and thus cannot explain the model underestimation of $\mathrm{Na}^{+}$in precipitation. The model underestimates $\mathrm{Na}^{+}$in precipitation at all sites, regardless of whether $\mathrm{Na}^{+}$in air is over- or underestimated, and no clear correspondence has been found in model performance for $\mathrm{Na}^{+}$in air and in precipitation between the sites. Also, the model underestimation of $\mathrm{Na}^{+}$in precipitation is about the same order of magnitude at both coastal and in-land sites. If we only look at the sites with concurrent 

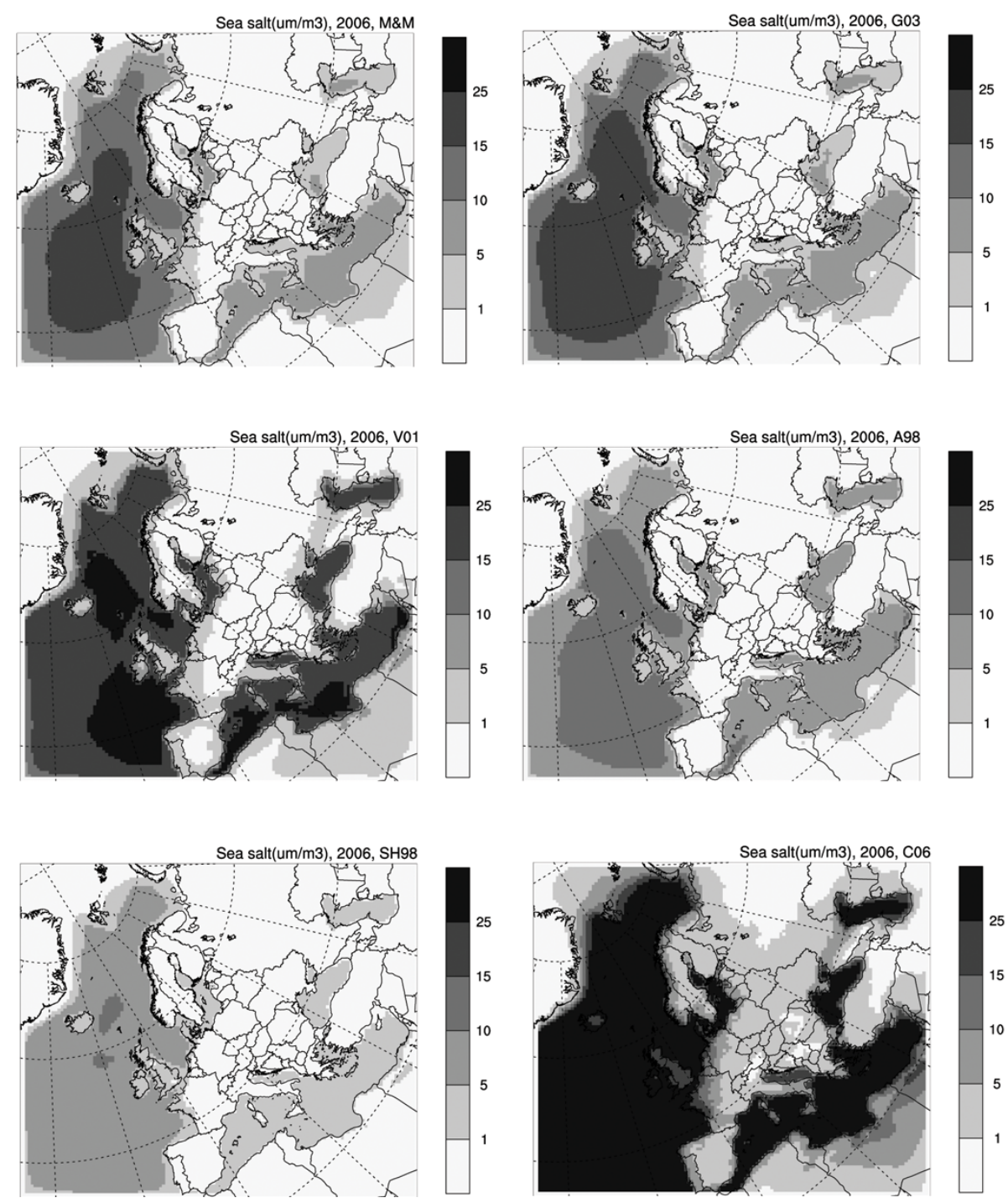

Fig. 2. Annual mean concentrations of sea salt in 2006 calculated with the standard EMEP model, i.e. using M \& M source function (upper left), and using source functions of G03 (upper right), V01 and A98 (middle row), and of SH98 and C06 (lower row).
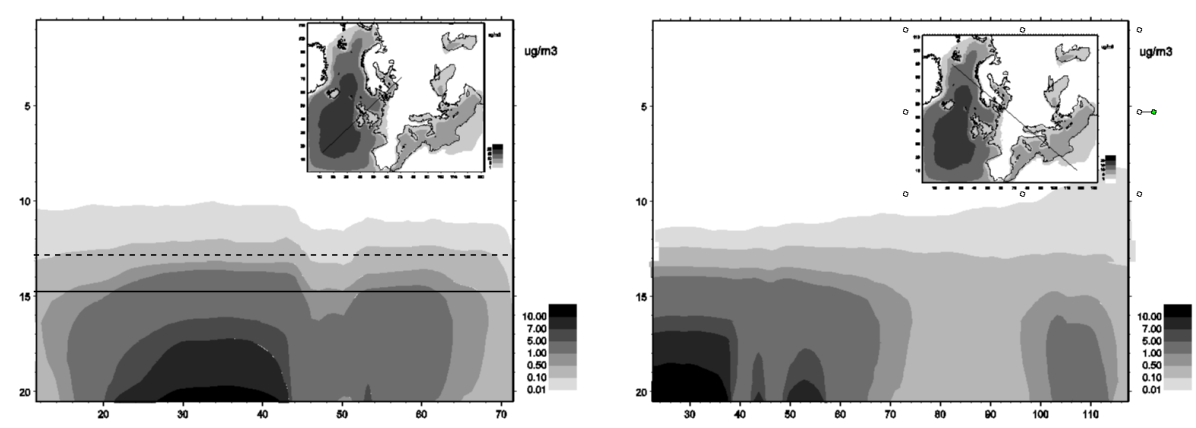

Fig. 3. Vertical cross-sections of annual mean sea salt concentration in 2006. The abscissa corresponds to the EMEP x-axes, while the ordinate axes show the centres of model vertical layers. The solid and dashed lines mark approximately 1 and $2 \mathrm{~km}$ heights respectively. 

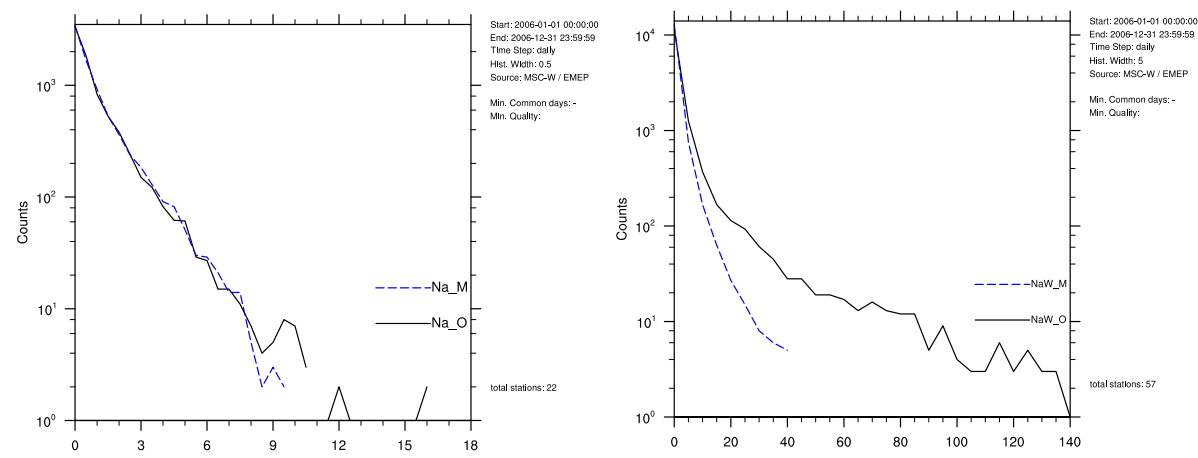

Fig. 4. Frequency distributions of calculated and observed $\mathrm{Na}^{+}$air concentrations (left panel) and $\mathrm{Na}^{+}$wet deposition (right panel) at EMEP sites in 2006.
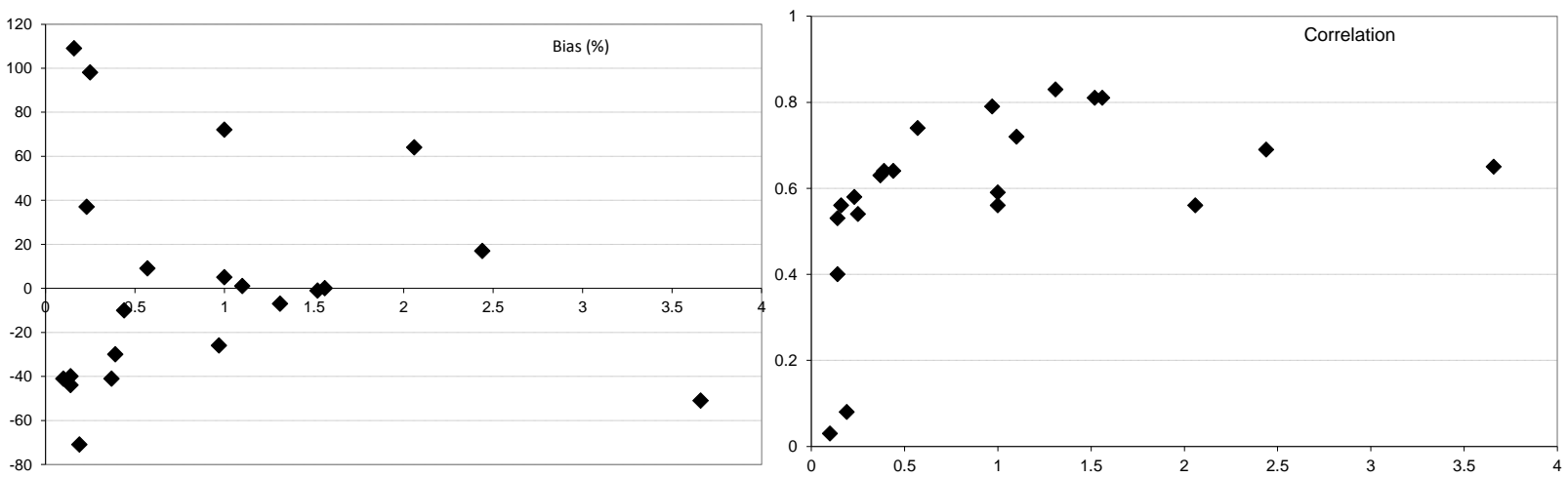

Fig. 5. Bias (\%) (a) and correlation (b) for calculated versus measured $\mathrm{Na}^{+}$in air in 2006 for EMEP sites ranked from left to right according to increasing measured $\mathrm{Na}^{+}$concentrations (given in $\mu \mathrm{g} \mathrm{m}^{-3}$ on the abscissa axis).

measurements of $\mathrm{Na}^{+}$in air and in precipitation, which are mainly coast sites, the model calculations are positively biased (by between 28 and $71 \%$ ) for $\mathrm{Na}^{+}$in air, while results for $\mathrm{Na}^{+}$in precipitation are negatively biased (between -55 and $-74 \%$ ) compared to observations. As seen in Table 2, annual accumulated wet deposition of $\mathrm{Na}^{+}$is underestimated by $69-77 \%$ in the period 2004-2007. Concurrent examination of daily time-series for $\mathrm{Na}^{+}$in air and precipitation shows no clear pattern in the model performance on days with and without precipitation.

The frequency distributions of calculated and observed daily wet deposition of $\mathrm{Na}^{+}$in 2006 (Fig. 4, right panel) show that the model under-predicts the number of occurrences for the whole range of wet deposition values, except from the smallest ones. This under-prediction grows with increasing $\mathrm{Na}^{+}$wet deposition values, and the model does not predict cases with $\mathrm{Na}^{+}$wet deposition exceeding $42 \mathrm{mg} \mathrm{m}^{-2}$ $\left(\mathrm{Na}^{+}\right.$wet deposition up to $125 \mathrm{mg} \mathrm{m}^{-2}$ were observed in 2006). It should be noted that the frequency distribution of precipitation in the model and observations are quite similar (not shown).
Seasonal analysis shows that the model reproduces well the average seasonal variation of sea salt for the period 2004 2007, characterised with minimum in summer and maximum in winter (Table 3). The model overestimates observed $\mathrm{Na}^{+}$ concentrations by about $25 \%$ in all seasons, and less so (by $13 \%)$ in the summer period. Model underestimation $\mathrm{Na}^{+}$ in precipitation is somewhat smaller in summer compared to the other seasons. Available verifications of precipitation input data cannot explain discrepancies between calculated and observed $\mathrm{Na}^{+}$in precipitation and $\mathrm{Na}^{+}$wet deposition, as the accumulated precipitation tends to be slightly overestimated.

For individual EMEP sites, the average model bias is $23 \%$ and the average temporal correlation with measurements is 0.56 in years $2004-2007$, though both vary considerably between the sites (Table A2). Calculated values of $\mathrm{Na}^{+}$air concentrations lie within $30 \%$ and $50 \%$ of measured values at $78 \%$ and $93 \%$ of the sites respectively. Figure 5 shows the annual mean model bias and correlation at the EMEP sites ranked from left to right according to increasing observed $\mathrm{Na}^{+}$concentrations for 2006. At the sites distant from the sea, mean $\mathrm{Na}^{+}$concentrations are typically below $0.5 \mu \mathrm{g} \mathrm{m}^{-3}$, with the lowest $\mathrm{Na}^{+}$levels being measured at the 
Table 3. Seasonal comparison between calculated and observed $\mathrm{Na}^{+}$concentrations in air and precipitation for the period $2004-2007$ (also bias for precipitation is shown in the last column). Here, observed (Obs) and model calculated (Mod) concentrations are in $\mu \mathrm{g} \mathrm{m}{ }^{-3}, \mathrm{Bias}$ is in $\%$.

\begin{tabular}{lrrrrrrrrrrr}
\hline \multirow{2}{*}{ Seasons } & \multicolumn{4}{c}{$\mathrm{Na}^{+}$in air } & & \multicolumn{4}{c}{$\mathrm{Na}^{+}$in prec } & \multirow{2}{*}{ Prec } \\
\cline { 2 - 4 } \cline { 9 - 10 } & Obs & Mod & Bias & $R$ & & Obs & Mod & Bias & $R$ & Bias \\
\hline JF & 1.00 & 1.16 & 25 & 0.64 & & 2.57 & 0.70 & -70 & 0.34 & 13 \\
MAM & 0.70 & 0.85 & 27 & 0.66 & & 1.37 & 0.42 & -69 & 0.45 & 9 \\
JJA & 0.54 & 0.60 & 13 & 0.61 & & 0.77 & 0.26 & -65 & 0.41 & -4 \\
SON & 0.78 & 0.93 & 23 & 0.68 & & 1.44 & 0.49 & -67 & 0.42 & -2 \\
\hline
\end{tabular}

Table 4. Average observed (Obs) and modelled (Mod) concentrations of $\mathrm{Na}^{+}$in $\mathrm{PM}_{10}$ and $\mathrm{PM}_{2.5}\left(\right.$ in $\mu \mathrm{g} \mathrm{m}^{-3}$ ) and correlation coefficient $(R)$ for EMEP intensive periods in June 2006 and January 2007.

\begin{tabular}{|c|c|c|c|c|c|}
\hline & & \multicolumn{2}{|c|}{ June 2006} & \multicolumn{2}{|c|}{ January 2007} \\
\hline & & $\mathrm{Na} \_\mathrm{PM}_{10}$ & $\mathrm{Na} \_\mathrm{PM}_{2.5}$ & $\mathrm{Na}_{2} \mathrm{PM}_{10}$ & $\mathrm{Na} \_\mathrm{PM}_{2.5}$ \\
\hline \multirow[t]{3}{*}{ NO01 } & Obs & 0.39 & 0.12 & 0.45 & 0.34 \\
\hline & Mod & 0.28 & 0.12 & 0.54 & 0.18 \\
\hline & $R$ & 0.67 & 0.46 & 0.33 & 0.48 \\
\hline \multirow[t]{3}{*}{ FI17 } & Obs & 0.21 & 0.12 & 0.27 & 0.12 \\
\hline & Mod & 0.23 & 0.09 & 0.39 & 0.09 \\
\hline & $\mathrm{R}$ & 0.40 & 0.88 & 0.79 & 0.76 \\
\hline \multirow[t]{3}{*}{ IT01 } & Obs & 0.38 & 0.14 & 0.91 & 0.17 \\
\hline & Mod & 0.11 & 0.04 & 0.68 & 0.19 \\
\hline & $R$ & -0.25 & 0.04 & 0.52 & 0.13 \\
\hline \multirow[t]{3}{*}{ DE44 } & Obs & 0.28 & 0.10 & 0.64 & 0.26 \\
\hline & Mod & 0.12 & 0.06 & 0.51 & 0.18 \\
\hline & $R$ & 0.88 & 0.81 & 0.68 & 0.63 \\
\hline
\end{tabular}

most far-off from the coast locations. The model bias tends to increase with the distance from the coats. For in-land sites, the bias can be both positive and negative, with the greatest underestimations found for most remote from the sea sites (SK04, SI08, DE03, AT02). It should be noted that at in-land sites also anthropogenic sources can contribute to sodium concentrations, whereas none of anthropogenic sources have been accounted for in the model. At the sites experiencing more or less direct influence from the sea, $\mathrm{Na}^{+}$concentrations are in a range of 0.6 to $3.7 \mu \mathrm{g} \mathrm{m}^{-3}$. Calculated $\mathrm{Na}^{+}$ in air are in a better agreement with observations at sites located closer to coasts than at in-land sites, with the model showing a slight tendency to overestimate the observations (though $\mathrm{Na}^{+}$is quite underestimated at IE08). As mentioned in Sect. 4, sea salt particles larger than $10 \mu \mathrm{m}$ can also be captured by filter pack samplers. It was observed that during sea salt episodes the coarse fraction was typically enhanced compared to that in long-range transported air masses at coastal and near-coastal sites. Given inevitable uncertainty associated with the upper size limit of model calculated sea salt, we do not think that on average this can be a major source of discrepancies between calculated and observed $\mathrm{Na}^{+}$in air.
However, larger model underestimations are indeed found during sea salt episodes.

The temporal correlation between calculated and measured $\mathrm{Na}^{+}$in air is rather poor at the most remote from the sea sites (AT02 and SK04), as accurate calculation of dayto-day variability of very low concentrations are indeed a difficult task. The correlation significantly improves with decreasing distance to the coast, but goes slightly down at coastal sites (IE01, IE06 and IE08). The latter could probably be explained by the non-representativeness of measurements at coastal stations for a grid cell of $50 \times 50 \mathrm{~km}^{2}$ used in the model calculations.

\subsection{Comparison with EMEP intensive measurements}

During EMEP intensive measurement periods in June 2006 and January 2007, measurements of $\mathrm{Na}^{+}$in $\mathrm{PM}_{10}$ and $\mathrm{PM}_{2.5}$ were performed at a number of sites. These measurements for facilitated evaluation of model calculated size distribution of sea salt between fine and coarse aerosols in summer and winter seasons. For comparison with model calculations in this work, we have selected only those sites, at which the data coverage was at least $75 \%$ of days during each of the measurement months. The selected sites are Birkenes (NO01), Virolahti (FI17), Montelibretti (IT01) and Melpitz (DE44) (the only exception is FI17, for which only 12 days with $\mathrm{Na} \mathrm{PM}_{2.5}$ data were available for June 2006).

Average for the intensive measurement periods values of observed (Obs) and modelled (Mod) air concentrations of $\mathrm{Na}^{+}$in $\mathrm{PM}_{10}$ and $\mathrm{PM}_{2.5}$ are provided in Table 4. Both model and observations give higher $\mathrm{Na}^{+}$air concentrations in January 2007 compared to June 2006, which is due to typically higher wind speeds in winter. The correlation (R) between calculated and measured $\mathrm{Na}^{+}$shows considerable variation between the sides and the months, ranging from -0.25 to 0.88 . The correlation is mostly better than 0.40 for NO01, FI17 and DE44, but it is poorer for IT01.

Figure 6 summarises the statistical analysis with respect to model's bias compared to observations at those four sites. Shown are the results for concentrations of $\mathrm{Na}^{+}$in $\mathrm{PM}_{10}$ $\left(\mathrm{Na}_{-} \mathrm{PM}_{10}\right)$ and separately for fine $\left(\mathrm{Na}_{-} \mathrm{PM}_{2.5}\right)$ and coarse $\mathrm{Na}^{+}$in June 2006 (left) and January 2007 (right). It should 

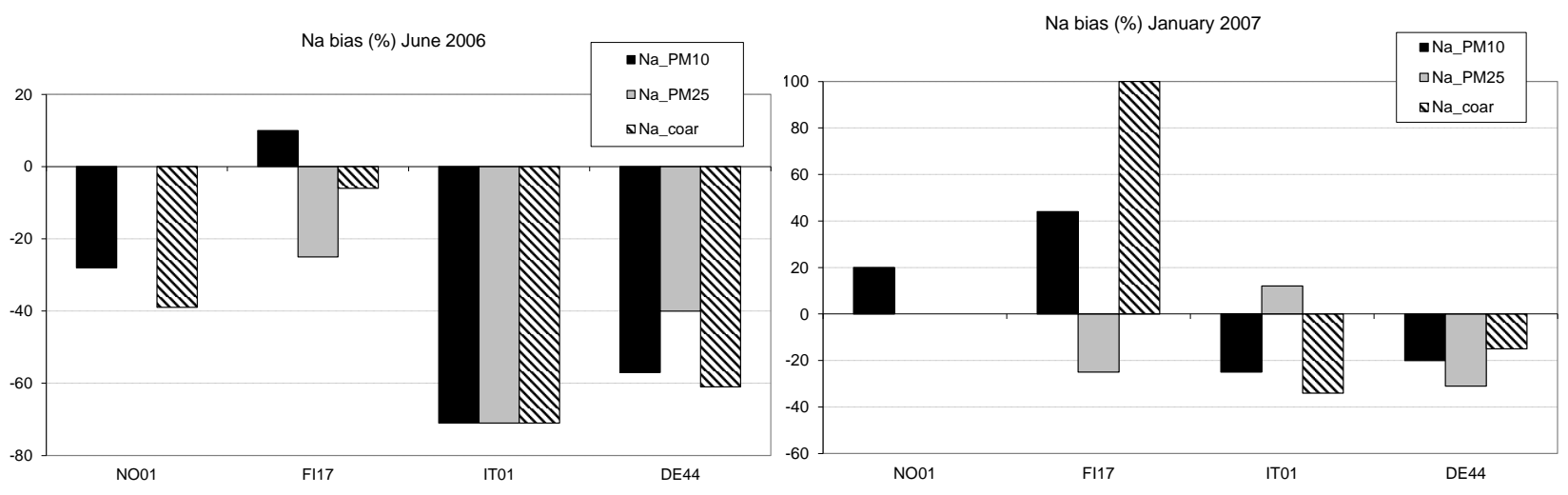

Fig. 6. Model bias for concentrations $\mathrm{Na}^{+}$in $\mathrm{PM}_{10}, \mathrm{Na}^{+}$in $\mathrm{PM}_{2.5}$ (fine $\mathrm{Na}^{+}$) and coarse $\mathrm{Na}^{+}$at Birkenes (NO01), Virolahti (FI17), Montelibretti (IT01) and Melpitz (DE44) in June 2006 (left) and January 2007 (right). Note: 1. the bias for Na_PM 2.5 is zero for NO01 in June 2006; 2. suspected erroneous data in January 2007 was excluded for NO01; 3. less days with measurements for Na_PM2.5 and Na_coar than for Na_PM10 at FI17.

be noted that concentrations of coarse $\mathrm{Na}^{+}$were not measured, but have been derived as the difference between measured $\mathrm{Na} \_\mathrm{PM}_{10}$ and $\mathrm{Na} \_\mathrm{PM}_{2.5}$. This means that they are affected by inaccuracies in measurements of both $\mathrm{Na}^{+}$in $\mathrm{PM}_{10}$ and $\mathrm{PM}_{2.5}$, what increases their uncertainty. Also, note that fewer daily measurements were available for $\mathrm{Na}^{+}$in $\mathrm{PM}_{2.5}$ (and thus for coarse $\mathrm{Na}^{+}$) than for $\mathrm{Na}^{+}$in $\mathrm{PM}_{10}$ at FI17, causing some inconsistency in the analysis.

$\mathrm{Na}^{+}$air concentrations in both fine and coarse fractions are underestimated by the model in the summer month of June 2006 (with the exception of $\mathrm{Na}^{+}$in $\mathrm{PM}_{10}$ at FI17). The underestimation of $\mathrm{Na}^{+}$concentrations is smaller (within $40 \%$ ) at NO01 and FI17, situated closer to the sea, compared to underestimation by between 40 and $70 \%$ at IT01 and DE44 in June 2006. In the winter month of January 2007, the underestimation of $\mathrm{Na}^{+}$in both size fractions is considerably smaller than in summer at IT01 and DE44, and the model tends to overestimate $\mathrm{Na}^{+}$concentrations at FI17 and NO01. Furthermore, compared to observations, the model tends to attribute a larger portion of $\mathrm{PM}_{10} \mathrm{Na}^{+}$to fine aerosols in June 2006, while it distribute somewhat too much $\mathrm{Na}^{+}$in the coarse mode in January 2007 (not shown here).

We look closer at the distribution of $\mathrm{Na}^{+}$between fine and coarse particles for DE44 (Melpitz), for which $\mathrm{Na}^{+}$measurements in $\mathrm{PM}_{10}$ and $\mathrm{PM}_{2.5}$ are available for the whole year of 2007. The daily time-series of $\mathrm{Na}^{+}$in $\mathrm{PM}_{10}$ and $\mathrm{PM}_{2.5}$ and coarse $\mathrm{Na}^{+}$are shown in Figure 7. The model quite closely reproduces observed $\mathrm{Na}^{+}$concentrations, somewhat underestimating $\mathrm{Na}^{+}$in all of the size fractions. $\mathrm{Na}^{+}$distribution between the two size fractions is fairly well calculated. Also, the model describes well the seasonal variation of $\mathrm{Na}^{+}$, however showing a tendency to underestimate $\mathrm{Na}^{+}$somewhat more in the warm period. Day-to-day $\mathrm{Na}^{+}$variation, including $\mathrm{Na}^{+}$pollution episodes, is also well calculated by the model.
In summary, the comparison of model results for $\mathrm{Na}^{+}$air concentrations with EMEP intensive measurements at four sites indicates that calculated sea salt fluxes are somewhat too small in summer, whereas they seem to be more accurate in winter. The reason for that could be too low wind speeds in summer as calculated by the meteorological model or inaccurate description of the wind speed dependence of sea spray flux. On the other hand, the resolution of the EMEP of $50 \times 50 \mathrm{~km}^{2}$ could be too coarse to accurately reproduce sea salt gradients.

The results also indicate a possibility of too efficient removal of sea salt aerosol from the air, as model underprediction of $\mathrm{Na}^{+}$air concentrations tends to increase at the sites farther from the sea.

On average, the modelled distribution of sea salt mass between fine and coarse aerosols is quite close to the observed one, namely the fraction of fine $\mathrm{Na}^{+}$mass within $\mathrm{Na}^{+}$in $\mathrm{PM}_{10}$ are on average 0.36 from the model and 0.4 from the measurements. Still, some seasonal discrepancies in size distribution between calculations and observations are found at individual sites, namely the model results suggest that more $\mathrm{Na}^{+}$resides in fine fraction in summer than in winter, which is not seen in the measurement data. This implies that the wind speed dependence of the size distribution of sea spray droplets flux calculated with M \& M parameterisation needs further testing and evaluation.

\section{Uncertainty study}

The performance of the model for sea salt strongly relies on the precision of calculations of sea spray production and sea salt size distribution at different ambient conditions. However, beside the accuracy of the sea spray source function, the model's ability of reproducing sea salt concentrations greatly depends on the quality of wind speed data used in 

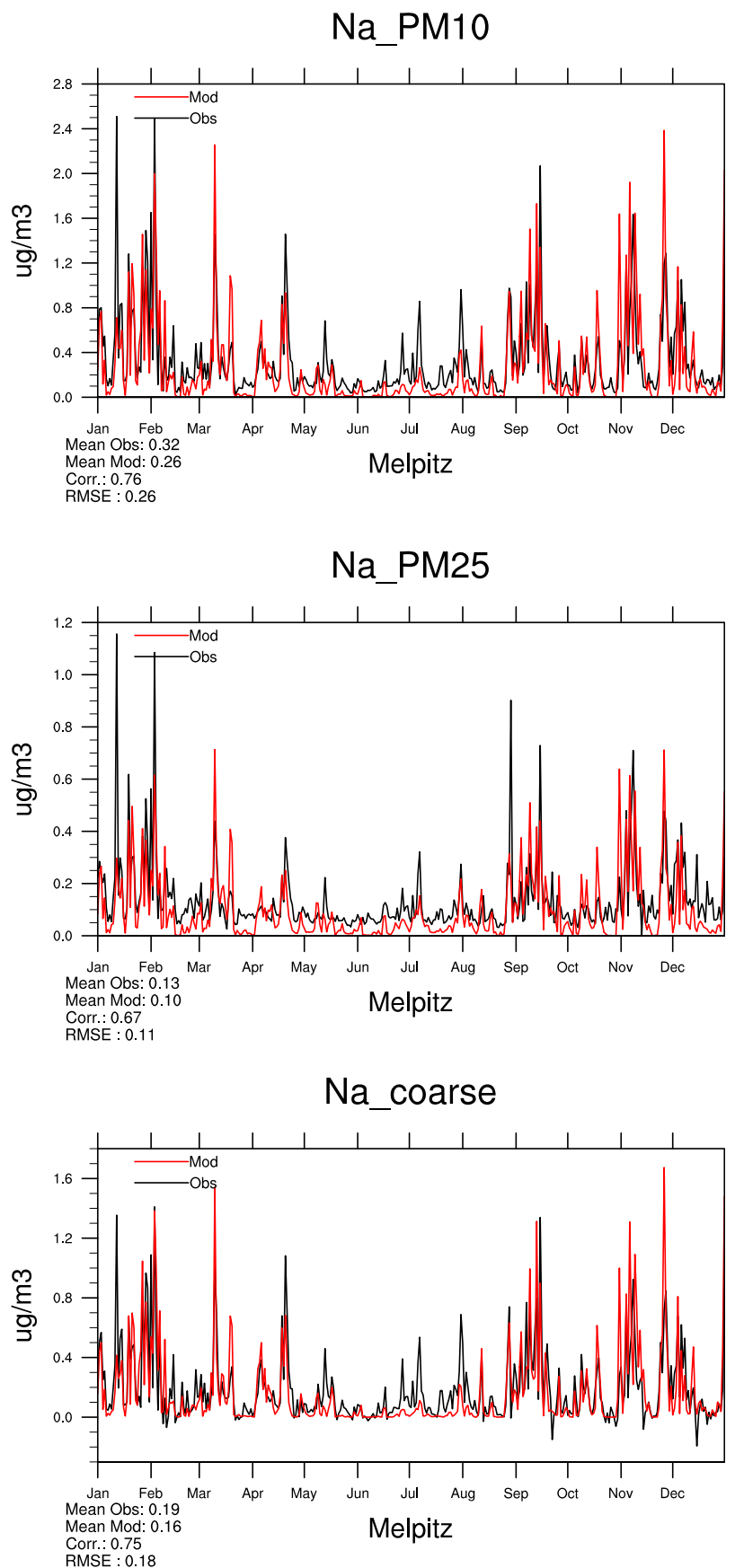

Fig. 7. Daily time-series of observed and model calculated air concentrations of $\mathrm{Na}^{+} \mathrm{PM}_{10}, \mathrm{PM}_{2.5}$ and coarse $\mathrm{PM}$ in 2007 at Melpitz, Germany (DE44).

calculations. Also, an accurate description of processes related to sea salt transport, dry and wet deposition is essential. For example, Pierce and Adams (2006) demonstrated the importance of model processes other than sea salt emissions parameterisation and cautioned against concluding that emissions parameterisation is superior to other processes and parameters when explaining the model results.
Table 5. Comparison statistics for annual mean calculated $\mathrm{Na}^{+}$air concentrations and observations in 2006, obtained with the EMEP model, using M \& M, G03, A98, SH98 and V01 source functions.

\begin{tabular}{lrrrrr}
\hline & $\begin{array}{r}\text { EMEP } \\
(\text { M \& M })\end{array}$ & G03 & A98 & SH98 & V01 \\
\hline N sites & 22 & 22 & 22 & 22 & 22 \\
Bias, \% & 12 & 25 & -10 & -40 & 120 \\
R & 0.79 & 0.78 & 0.77 & 0.76 & 0.77 \\
RMSE & 0.61 & 0.70 & 0.58 & 0.70 & 1.65 \\
\hline
\end{tabular}

A series of test runs has been carried out in order to study the effect of uncertainties in sea salt generation and removal efficiency on model results, trying to reconcile them with observations. In this section, we compare model sea salt results using different source functions. We also investigate the effect of dry deposition and wet scavenging velocities on calculated sea salt.

\subsection{Effect of sea spray source function}

As seen in Fig. 2, differences in calculated sea salt fields can be quite large when using different sea spray source functions. In this section, we compare results from the standard EMEP model run using four alternative parameterisations of sea salt production with observations in 2006. Tables 5 and 6 summarise the comparison statistics for $\mathrm{Na}^{+}$concentrations calculated using source functions M \& M, G03, A98, SH98 and V01 (see for explanation Sects. 2.1 and 5.1). The statistics are shown for the whole year of 2006 and for four seasons.

The main findings from Tables 5 and 6 are:

- M\&M and G03 parameterisations give quite similar results for $\mathrm{Na}^{+}$air concentrations. They overestimate the annual mean $\mathrm{Na}^{+}$by $12 \%$ and $25 \%$ respectively in 2006;

- A98 and SH98 underestimate $\mathrm{Na}^{+}$air concentrations by $10 \%$ and $40 \%$ respectively. Lower concentrations of sea salt produced by A98 is partly due to its underestimation of sea spray production for droplets under $2 \mu \mathrm{m}$ compared to M\& M and G03 (see Fig. 2). On the other hand, A98 calculates a greater mass of larger sea salt aerosols, especially at lower wind speeds. Also, Guelle et al. (2001) pointed to a very efficient sea salt production at low wind speeds as a probable reason for overestimations of sea salt at eight stations around the globe by A98 source function;

- V01 parameterisation gives far too high sea salt concentrations, overestimating the $\mathrm{Na}^{+}$observations by $120 \%$;

- for different seasons, the best agreement with observations for $\mathrm{M} \& \mathrm{M}$ and $\mathrm{G} 03$ predictions of $\mathrm{Na}^{+}$air 
Table 6. Seasonal bias (in \%) and correlation $(R)$ for calculated $\mathrm{Na}^{+}$air concentrations compared with observations in 2006 , obtained with the EMEP model using M \& M, G03, A98, SH98 and V01 source functions. Note: year (daily) statistics compare calculated and observed $\mathrm{Na}^{+}$concentrations on a daily basis.

\begin{tabular}{|c|c|c|c|c|c|c|c|c|c|c|}
\hline & \multicolumn{2}{|c|}{ EMEP (M \& M) } & \multicolumn{2}{|c|}{ G03 } & \multicolumn{2}{|c|}{ A98 } & \multicolumn{2}{|c|}{ SH98 } & \multicolumn{2}{|c|}{ V01 } \\
\hline & Bias & $R$ & Bias & $R$ & Bias & $R$ & Bias & $R$ & Bias & $R$ \\
\hline Year (daily) & 12 & 0.69 & 25 & 0.68 & -10 & 0.53 & -40 & 0.68 & 121 & 0.43 \\
\hline winter & 30 & 0.62 & 49 & 0.60 & -4 & 0.56 & -27 & 0.60 & 124 & 0.49 \\
\hline spring & 10 & 0.67 & 25 & 0.67 & -11 & 0.56 & -40 & 0.66 & 114 & 0.48 \\
\hline summer & 6 & 0.70 & 13 & 0.69 & 26 & 0.52 & -47 & 0.69 & 245 & 0.44 \\
\hline autumn & 5 & 0.71 & 13 & 0.71 & 27 & 0.58 & -45 & 0.69 & 73 & 0.49 \\
\hline
\end{tabular}

Table 7. Comparison of $\mathrm{Na}^{+}$in air calculated using three meteorological drivers (PARLAM-PS, HIRLAM-v7.1 and ECMWF) with the

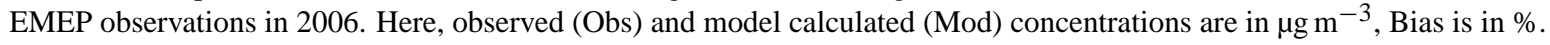

\begin{tabular}{|c|c|c|c|c|c|c|c|c|c|c|}
\hline & \multirow[b]{2}{*}{ Obs } & \multicolumn{3}{|c|}{ PARLAM-PS } & \multicolumn{3}{|c|}{ HIRLAM-v7.1 } & \multicolumn{3}{|c|}{ ECMWF } \\
\hline & & Mod & Bias & $\mathrm{R}$ & Mod & Bias & $R$ & Mod & Bias & $R$ \\
\hline Year & 0.91 & 1.02 & 12 & 0.69 & 0.94 & 4 & 0.83 & 0.9 & 0 & 0.82 \\
\hline winter & 0.84 & 1.09 & 30 & 0.62 & 0.95 & 13 & 0.66 & 0.81 & -4 & 0.64 \\
\hline spring & 0.89 & 0.97 & 10 & 0.67 & 0.98 & 11 & 0.66 & 0.91 & 2 & 0.69 \\
\hline summer & 0.64 & 0.68 & 6 & 0.70 & 0.56 & -13 & 0.75 & 0.79 & 23 & 0.73 \\
\hline autumn & 1.06 & 1.11 & 5 & 0.71 & 1.07 & 1 & 0.72 & 0.97 & -9 & 0.67 \\
\hline
\end{tabular}

concentrations is found in summer-autumn, when positive bias decreases. Calculated with A98 $\mathrm{Na}^{+}$concentrations are closest to the observations in winter-spring (a small negative bias), while they exceed by 26-27\% observations in summer-autumn. Those differences in seasonal predictions are due to different wind speed dependence of sea salt fluxes calculated by these source functions. Compared to M \& M and G03, A98 calculates larger sea salt productions at low wind speeds which are more typical for summer-autumn months. Furthermore, SH98 considerably underestimates $\mathrm{Na}^{+}$ air concentrations in all seasons, though somewhat less in winter, while V01 is found to significantly overestimate $\mathrm{Na}^{+}$;

- the spatial correlation between annual mean calculated and measured $\mathrm{Na}^{+}$concentrations is quite similar for all parameterisations, with the correlation coefficient ranging between 0.76 for $\mathrm{SH} 98$ and 0.79 for M \& M. The spatio-temporal correlation (between calculated and measured daily $\mathrm{Na}^{+}$concentrations for all sites) and the correlation for the individual seasons are best when applying the M \& M source function, closely followed by G03 and SH98, and considerably lower correlation is found for A98 and V01.

The comparison results of $\mathrm{Na}^{+}$air concentration, calculated with the EMEP model using the five source functions, with observations at the individual EMEP stations are provided in
Appendix (Table A2). On average, $M$ \& $M$ yields the best agreement with observed $\mathrm{Na}^{+}$in terms of bias and correlation, i.e. it gives the best temporal correlation between calculated and measured $\mathrm{Na}^{+}(0.58)$ and next to the best bias of +23 .

\subsection{Effect of meteorology}

Calculated emission rates of sea salt crucially depend on the wind speed, thus even a small incorrectness in wind speed data can result in quite wrong predictions of sea salt fluxes. To see how different meteorological input affects calculated sea salt, model runs have been performed with different meteorological drivers, i.e. PARLAM-PS, HIRLAM version 7.1 and ECMWF models. The results of the runs and comparison with observations at EMEP sites are summarised in Table 7.

Compared with $\mathrm{Na}^{+}$measurements, there is a certain improvement in model calculated sea salt concentrations using HIRLAM-v7.1 and ECMWF (IFS) meteorology. The positive bias decreases from 12 (PARLAM-PS) to 4 and $0 \%$, and the spatial correlation improves from 0.69 (PARLAM-PS) to 0.83 and 0.82 respectively. Also, different sea salt seasonal variations are predicted using different meteorological data. PARLAM-PS and HIRLAM give somewhat larger seasonal variability compared to observations, while flatter seasonality is calculated with ECMWF meteorology. 
Table 8. Model bias (in \%) for concentrations of $\mathrm{Na}^{+}$in air (in $\mu \mathrm{g} \mathrm{m}^{-3}$ ) and precipitation (in $\mathrm{mg}^{-1}$ ) in sensitivity tests to scavenging ratio $W$, below-cloud washout efficiency $(\mathrm{E})$, dry deposition reduction and including larger aerosols for 2006.

\begin{tabular}{lrrrrrrr}
\hline & $W=1 \times 10^{6}$ & $W=1.6 \times 10^{6}$ & $W=2 \times 10^{6}$ & $E=1$ & $0.5 \mathrm{Vd}$ & Size ext. & $\begin{array}{r}\text { Size ext. } \\
W=2 \times 10^{6}\end{array}$ \\
\hline $\mathrm{Na}^{+}$air & 12 & 5 & -2 & -1 & 66 & $12^{*}$ & $-2^{*}$ \\
$\mathrm{Na}^{+}$prec & -64 & -62 & -62 & -65 & -51 & -51 & -49 \\
\hline
\end{tabular}

* Sea salt aerosols smaller than approximately $10 \mu \mathrm{m}$

Unfortunately, verification of wind speed from PARLAMPS, HIRLAM and ECMWF (IFS) is only available over land. Compared to SYNOP meteorological observations, PARLAM-PS is unfavourably characterised with the largest mean absolute error and highest error standard deviation (A. Benedictow, personal communication, 2011). Beside the wind speed, also other meteorological parameters modify sea salt concentrations and distribution. In particularly, precipitation has significant effect on airborne sea salt, efficiently scavenging the aerosols.

\subsection{Effect of wet deposition}

As shown above, $\mathrm{Na}^{+}$concentrations in precipitation are considerably underestimated by the model, while $\mathrm{Na}^{+}$air concentrations are slightly overestimated for all sea salt source functions tested. To see what processes could be responsible for those discrepancies, we have tested the possibility of the model (1) underestimating wet scavenging and (2) over-predicting the efficiency of dry deposition of sea salt.

Being very hygroscopic, sea salt aerosols are efficiently removed from the clouds by rain drops. Most sea salt rainout takes place in the lower part of the cloud, where the precipitation intensity is the largest. The washout below clouds depends on the aerosol size and is much more efficient for coarse sea salt than for fine sea salt. In the model, the belowcloud scavenging is about 2.5 times less efficient for coarse sea salt and as much as 10 times less efficient for fine sea salt compared to in-cloud rainout. On the other hand, relatively more sea salt mass is found in the lower altitudes, likely below the clouds, especially over the source regions.

Sensitivity tests have been performed for both in-cloud and below-cloud scavenging of sea salt. The model's wet deposition scheme uses scavenging ratios to calculate aerosol removal from the cloud layers. In the base runs presented in the previous sections, the scavenging ratio $W=1 \times 10^{6}$ was used. To investigate the effect of wet scavenging ratio on calculated $\mathrm{Na}^{+}$concentrations, additional calculations have been performed using $W=1.6 \times 10^{6}$ and $2 \times 10^{6}$. The increase of scavenging ratio by factors of 1.6 and 2 results in a rather modest decrease of $\mathrm{Na}^{+}$in air (with model bias changing from $12 \%$ to $5 \%$ and $-1 \%$ respectively) and in an in- significant or no increase in $\mathrm{Na}^{+}$in precipitation (Table 8). This is probably because the efficiency of sea salt scavenging in clouds is already so high, that most of aerosol mass gets rained out anyway; hence the further increase of scavenging ratio appears to add only very little to scavenged sea salt mass. The effect of increasing wet scavenging ratio appears less pronounced in sites most remote from sea, since most sea salt particles are likely to get scavenged before they reach the in-land sites. Further increase of scavenging ratio causes in fact a decrease in wet deposition of sea salt over land, as even a greater portion of sea salt is removed by precipitation already over oceans.

Further, we have increased the below-cloud washout efficiency to 1.0 for fine and coarse aerosols (from 0.4 and 0.8 respectively). As a result, the positive bias for $\mathrm{Na}^{+}$in air is eliminated, but the negative bias for $\mathrm{Na}^{+}$in precipitation gets even larger (Table 8). Also in this case, more efficient wet scavenging means that even more of sea salt is removed from the air over the oceans, resulting in overall lower $\mathrm{Na}^{+}$ concentrations in air and precipitation over land.

\subsection{Effect of dry deposition}

Hypothesizing that too efficient dry deposition in the model could remove too much sea salt mass from air during dry periods and contribute to the underestimation of $\mathrm{Na}^{+}$in precipitation, we have looked at the effect of dry deposition reduction. A model run has been made, where dry deposition velocity was decreased by $50 \%$. This has increased $\mathrm{Na}^{+}$ concentrations in air by $48 \%$ and $\mathrm{Na}^{+}$concentrations in precipitation by $38 \%$ at the EMEP sites on average. In this test, the model overestimates $\mathrm{Na}^{+}$in air by $66 \%$, whereas it still underestimates $\mathrm{Na}^{+}$in precipitation by $51 \%$ (Table 8). It can be noted that the reduction of dry deposition velocity is found to cause the greatest increase in calculated $\mathrm{Na}^{+}$air concentrations for in-land sites.

\subsection{Including larger sea salt particles}

Discrepancies between calculated and measured sea salt concentrations can occur due to inconsistency in the upper "cutoff" size of sea salt aerosols. The standard EMEP model is set up to calculate approximately $\mathrm{PM}_{2.5}$ and $\mathrm{PM}_{10}$. The upper dry diameter of generated sea salt particle is set to $5 \mu \mathrm{m}$, 
which would correspond to aerosol ambient diameters between 7.5 and $10.6 \mu \mathrm{m}$ at a relative humidity between $40 \%$ and $80 \%$. As said in Sect. 4, filter-pack samplers collect particles with aerodynamic diameters of approximately $10 \mu \mathrm{m}$ (at ambient conditions), though there is no defined cut-off size. For sampled $\mathrm{Na}^{+}$in precipitation, there is practically no cut-off size for collected sea salt aerosols. Some amount of sea salt particles larger that e.g. $10 \mu \mathrm{m}$ can also be present in the air and, when scavenged, they will contribute to $\mathrm{Na}^{+}$concentrations in precipitation. The fraction of sea salt particles larger than $10 \mu \mathrm{m}$ will decrease considerably with increasing distance from the sea coast due to their fast gravitational settling. Therefore, the effect of not accounting for those "giant" sea salt aerosols is expected to be more pronounced at sites close to the sea shore than at in-land sites.

To estimate the contribution of sea salt particles larger than $10 \mu \mathrm{m}$ to $\mathrm{Na}^{+}$concentrations, a new model run for 2006 has been performed, in which sea salt aerosols with dry diameters up to $17 \mu \mathrm{m}$ were included. For $\mathrm{Na}^{+}$in air, these results overestimate measured concentrations by $46 \%$ (as compared to $12 \%$ in the base run) (Table 8). As expected, somewhat greater increase in calculated $\mathrm{Na}^{+}$is seen for sites close to the sea coasts (not shown). The negative bias for $\mathrm{Na}^{+}$in precipitation is only reduced to $-51 \%$ compared to $-64 \%$ in the base run.

\subsection{Sea salt emissions}

Finally, a series of tests been made in which both the sea salt flux (or $10 \mathrm{~m}$ wind speed) and sea salt wet scavenging were increased. The tests have shown that quite a significant increase of wet scavenging efficiency was required to balance the enhanced sea salt production in order to obtain sound results. When varying the value of scavenging ratio within a realistic range, the best results with respect to the average statistics is achieved by increasing sea salt production by a factor of 1.5 (or increasing $10 \mathrm{~m}$ wind by $10 \%$ ), and raising scavenging ratio to $2.5 \times 10^{6}$. Then, $\mathrm{Na}^{+}$in precipitation is underestimated by about $40 \%$, whereas of $\mathrm{Na}^{+}$in air is overestimated by about $25 \%$. The results tend to overestimate sea salt at coastal sites, while underestimate at in-land sites, thus exaggerating sea salt regional gradients. Summarising these tests, quite considerable (however within reasonable limits) simultaneous increase of sea salt production and wet scavenging failed to eliminate underestimation of $\mathrm{Na}^{+}$in precipitation, while calculated $\mathrm{Na}^{+}$air concentrations get too high.

As described in Sect. 3.2, sea salt flux is immediately mixed within model's lowest layer (approximately $90 \mathrm{~m}$ thick). Blanchard et al. (1984) reported marked sea salt gradients in the lowest 50 in the marine atmosphere, though the largest gradients were probably due to very large particles $\left(\mathrm{d}_{0}>40 \mu \mathrm{m}\right)$. The assumption on immediate mixing, applied in the EMEP model, is likely to contribute to underestimation of surface concentrations associated with the source areas, i.e. over sea and in the proximity to coasts. On the other hand being distributed closer to the ground, sea salt will be more efficiently deposited, which will shorten its lifetime and transport distance.

Preliminary tests for January 2008, in which emitted sea salt is distributed within a layer of approximately $20 \mathrm{~m}$, show considerably (up to 50-100\%) higher sea salt concentrations over seas compared to standard runs. Compared to the standard runs, observed $\mathrm{Na}^{+}$concentrations are larger overestimated at coastal sites and larger underestimated at in-land ones. For all stations, the average bias goes up from $-5 \%$ to $24 \%$ and spatial correlation goes down from 0.79 to 0.70 when the lowest layer is reduced from $90 \mathrm{~m}$ to $20 \mathrm{~m}$.

\subsection{Effect of sea surface roughness}

Another parameter effecting sea salt production is the roughness of sea, which is described through Charnock's constant $\beta$ (Eq. 5). The value of $\beta$ has recently been changed from 0.032 to 0.00114 , which is considered to be more consistent with the present description of boundary layer processes in the EMEP model. A lower value of $\beta$ represents a less rough sea and thus a larger wind speed at $10 \mathrm{~m}$ height which, in turn, increases the fluxes of sea salt.

The sensitivity tests show that on average, the calculated sea salt concentrations are only $5 \%$ lower when using $\beta=$ 0.032 compared to $\beta=0.0114$, with somewhat larger difference in winter and spring. This slightly decreases model's bias from 12 to $7 \%$ compared against $\mathrm{Na}^{+}$observations in 2006. The correlation between calculated and observed $\mathrm{Na}^{+}$ does not appear to be affected by varying Charnock's parameter.

\subsection{Unaccounted processes}

Water salinity. The content of salt in oceanic surface water varies from below $10 \%$ in the Baltic Sea and about $18 \%$ in the Black Sea to above $37 \%$ in the middle of NE Atlantic and $38 \%$ in the Mediterranean Sea. There are experimental indications that water salinity can affect the generation of sea salt. Mårtinsson et al. (2003) measured that for aerosols smaller than $0.2 \mu \mathrm{m}$ salinity did not affect the original droplet number production, but only the size distribution of dry sea salt particles. However, for larger aerosols, the total volume of generated sea spray droplets increased with increasing water salinity. In their experiments, sea salt concentrations at salinity $37 \%$ were about an order of magnitude larger than those at salinity $9.2 \% o$. In the present work, an average water salinity of $33 \%$ is assumed, according to parameterisation by Mårtinsson et al. (2003). The first attempt we are aware of to include the effect of water salinity on sea salt production has been made by Sofiev et al. (2011), based on laboratory measurements from Mårtinsson et al. (2003).

Surf zone. Based on field measurements, de Leeuw et al. (2000) estimated that sea spray production could be a factor of 2 greater in surf zone compared to the open ocean. 
An accurate accounting for sea spray contribution from a surf zone in the regional model is not a trivial task, as it requires gridding of the surface zone. Since the surf zone is rather narrow, its relative area, and thus contribution to the total sea spay, will be relatively small within the EMEP $50 \times 50 \mathrm{~km}^{2}$ grid cell. This is supported by work of Gong et al. (2002), who showed that surf zone sea salt flux was much smaller compared to that on an open ocean and concluded that the surfing contribution to the total sea salt production was negligible on a regional scale. We are not aware of any regional/global model presently including this effect in calculations.

\section{Comparison of sea salt from EMEP and SILAM model}

To test the robustness of our sea salt model results, calculations from the EMEP model are compared with those from SILAM model (Sofiev et al., 2006) for the year 2007.

\subsection{Sea salt description in the SILAM model}

Similar to EMEP model, SILAM's sea salt emission parameterisation is based on the parameterisation of Monahan et al. (1986) and the data of Mårtensson et al. (2003), which are combined into a unified set of functions. The parameterisation takes into account the effects of wind speed, salinity, and water temperature and covers sea salt particles with dry diameter from $20 \mathrm{~nm}$ to $10 \mu \mathrm{m}$.

Briefly, observations extracted from the Mårtensson et al. (2003) paper for sea water surface temperature $298 \mathrm{~K}$ and sea water salinity $33 \%$ o were used to extrapolate the scheme from Monahan et al. (1986) to particle sizes down to $20 \mathrm{~nm}$. This resulted in a single source function for particles with diameters from $20 \mathrm{~nm}$ to $10 \mu \mathrm{m}$ for these reference conditions:

$$
\begin{aligned}
&\left(\frac{d F_{0}}{d d_{\mathrm{d}}}\right)_{33 \% 0,25^{\circ}}= 6.9 \times 10^{5} \times \frac{\exp \left(^{-0.12} / d_{\mathrm{d}}\right)}{0.05+\exp \left(^{-0.1} / d_{\mathrm{d}}\right)} \times \frac{1+0.05 d_{\mathrm{d}}^{1.05}}{d_{\mathrm{d}}^{3}} \\
& \times 10^{1.6 \exp \left(-\left(\frac{1.1 \log d_{\mathrm{d}}}{0.8}\right)^{2}\right)}
\end{aligned}
$$

To calculate sea salt production for other water temperatures and salinities, correction factors are applied which were derived based on the experimental data used in Mårtensson et al. (2003). The full description of the parameterisation in the SILAM model can be found in Sofiev et al. (2011).

For this study, sea salt in five size fractions has been calculated, i.e. for dry diameters in the ranges $0.01-0.1$, $0.1-1.0,1.0-2.5,2.5-10$, and $10-30 \mu \mathrm{m}$. The computations with SILAM have been performed with meteorological fields from the European Centre for Medium-Range Weather Forecasts $(E C M W F)$ at the grid of $20 \times 20 \mathrm{~km}^{2}$. Compared to the EMEP calculation domain, SILAM's grid covers a smaller area of the North Atlantic Ocean, starting at $17^{\circ} \mathrm{W}$ and $33^{\circ} \mathrm{N}$ (left lower corner).

\subsection{Comparison of results}

Air concentrations of $\mathrm{Na}^{+}$calculated with the EMEP and the SILAM models have been compared with EMEP measurements in 2007. For comparison with observations, sea salt aerosols in the first four size fractions (up to $10 \mu \mathrm{m}$ of dry diameter) from the SILAM model have been included, whereas sea salt aerosols up to about $10 \mu \mathrm{m}$ of ambient diameter in the EMEP model have been considered. $\mathrm{Na}^{+}$concentrations have been derived as $31 \%$ of the mass of sea salt concentrations.

It is useful to outline the differences between the models, relevant when interpreting calculation results. In addition to differences in the formulation of sea spray generation (Sect. 8.1), the SILAM model uses a finer representation of sea salt size distribution, i.e. assuming four size fractions, while the EMEP model aggregates sea salt aerosols into two fractions (fine and coarse). This has an effect on calculated efficiency of sea salt removal, particularly through dry deposition. Due to the better resolution, the SILAM model is expected to be more capable of reproducing concentrations observed in a proximity to the sea, given typically large coastal sea salt gradients. Furthermore, different meteorological drivers have been used in the runs, namely ECMWF model for the SILAM and HIRLAM model for EMEP. In particular, wind strength over seas is a crucial parameter for sea salt production.

For EMEP calculations, HIRLAM meteorological fields were produced on $0.2 \times 0.2^{\circ}$ grid and interpolated to EMEP $50 \times 50 \mathrm{~km}^{2}$ grid. Verification with surface wind observations at SYNOP sites shows very little difference between the original and interpolated wind speeds. No verification over seas was possible though. However, comparison of wind maps on $0.2 \times 0.2^{\circ}$ and $50 \times 50 \mathrm{~km}^{2}$ grids showed that the interpolated fields represented the wind field at the finer resolution fairly well, except for some areas with very strong wind gradients associated with atmospheric fronts.

Figure 8 compares $\mathrm{Na}^{+}$air concentrations from the EMEP and SILAM models with observed values, ranking the sites according to decreasing measured concentrations (crudely representing the increasing distance from the sea coast). The results of statistical analysis are summarised in Table A3. Both models realistically reproduce the observed distribution of sea salt concentrations. The spatial correlation between calculated and measured $\mathrm{Na}^{+}$is 0.73 for EMEP and 0.78 SILAM calculations. For about two thirds of the sites, the models calculate quite close values of $\mathrm{Na}^{+}$concentrations, whereas significant discrepancies are found at Finnish and Irish stations. Both models somewhat underestimate $\mathrm{Na}^{+}$ concentrations at about $70 \%$ of the sites, with largest underestimation at coastal Irish site IE08. Both models considerably overestimate $\mathrm{Na}^{+}$at Norwegian sites NO15 and NO39 (SILAM also overestimates at NO01 and NO55). Large overestimation by the EMEP model of $\mathrm{Na}^{+}$at FI09 and FI17 can partly be explained by not accounting for the effect of sea 
water salinity on sea salt generation. A simple model test, in which sea salt production from the Baltic Sea is reduced by a factor of five, reduces biases from 498 to $200 \%$ at FI09 and from $128 \%$ to $15 \%$ at FI11. Another probable reason for those overestimations is a relatively coarse resolution of the EMEP model. The site FI09 is situated on a small island, the area of which occupies less than $1 \%$ of the EMEP grid cell and the observations are thus not representative for the whole of $50 \times 50 \mathrm{~km}^{2}$ grid cell. Similarly, the site FI17 is not quite representative, as it is located in the very corner of a grid cell, which has $69 \%$ of its area covered by the Baltic Sea. Calculated $\mathrm{Na}^{+}$concentrations drop from $0.51 \mu \mathrm{g} \mathrm{m}^{-3}$ to $0.15-0.2 \mu \mathrm{g} \mathrm{m}^{-3}$ in the adjacent grids, which agrees better with observed value.

The temporal correlation between calculated and measured daily $\mathrm{Na}^{+}$air concentrations is quite variable for both models. On average, the correlation tends to be somewhat better at the sites at short and medium distances from the sea compared to in-land sites. In general, the EMEP model shows correlation better than SILAM at Danish, Finnish and Slovakian sites, while $\mathrm{Na}^{+}$from SILAM correlates better with observations at some of the German, Austrian and some of the Norwegian and Irish sites (Table A3). The differences in temporal correlations of calculations with measurements are to a large degree due to differences in the wind fields from the HIRLAM and ECMWF models used in EMEP and SILAM calculations.

\section{Summary and outlook}

We have used the EMEP Unified model (version rv3.1) to assess sea salt concentrations over Europe. The ability of the model to reproduce sea salt observations, both in air and precipitation, for multiple years has been evaluated, with focus on studying the effects of uncertainties in sea salt production and lifetime on model results.

As a part of the uncertainty study, a series of model calculations has been performed using different source functions for sea spray production. Based on a critical review of the documentation available in scientific literature, several sea spray source functions have been selected for our study, namely from Mårtensson et al. (2003), Monahan et al. (1986), Andreas (1998), Smith and Harrison (1998), Vignati et al. (2001), Gong (2003) and Clarke et al. (2006). The box-model study has provided insight in the differences between the source functions with respect to calculated intensity and wind speed dependence of sea spray fluxes, and the size distribution of generated sea salt aerosols (as outlined in Sect. 5.1).

Further, the selected sea salt source functions have been tested within a regional EMEP model. EMEP model calculations for 2006 show that largest sea salt concentrations are produced by $\mathrm{C} 06$ source function, followed by those calculated using V01, while SH98 parameterisation gives the low-

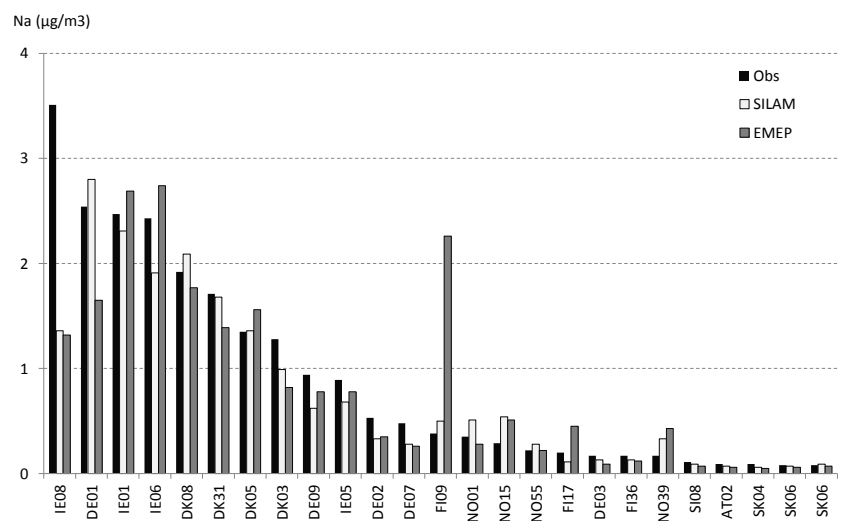

Fig. 8. Annual mean $\mathrm{Na}^{+}$air concentrations at EMEP sites in 2007: observed (black) and from the SILAM (white) and the EMEP (grey) models with observed values. The sites are ranked according to decreasing measured concentrations.

est sea salt concentrations. Lying between those high and low estimates, sea salt concentrations from M \& M (i.e. combination of Monahan et al. (1986) and Mårtensson et al. (2003) source functions) and G03 are quite close, whereas results given by $\mathrm{A} 98$ are somewhat lower.

Compared to EMEP observations for 2006, EMEP model calculations using M \& M and G03 parameterisations overestimate annual mean $\mathrm{Na}^{+}$air concentrations by 12 and $25 \%$ respectively. Calculations with A98 and SH98 underestimate $\mathrm{Na}^{+}$air concentrations on average by 10 and $40 \%$ respectively. V01 parameterisation overestimates observed $\mathrm{Na}^{+}$by as much as $120 \%$, whereas $\mathrm{Na}^{+}$air concentrations obtained with $\mathrm{C} 06$ exceed measured values by almost an order of magnitude. The spatial correlation between calculated and measured annual mean $\mathrm{Na}^{+}$concentrations is quite similar for all parameterisations, with the correlation coefficient ranging between 0.76 for SH98 and 0.79 for M \& M. The differences are found in the seasonal performance for sea salt calculated with the EMEP model, when different source functions are used. At individual measurement sites, the best temporal correlations are obtained with $\mathrm{M} \& \mathrm{M}$ source function, closely followed by G03 and SH98, while considerably lower correlations are found for A98 and V01. The results in terms of model bias are somewhat variable. On average for all sites, $\mathrm{M} \& \mathrm{M}$ shows the most promising results, providing the best temporal correlation of 0.58 and next best bias of $+23 \%$ compared with observed $\mathrm{Na}^{+}$air concentrations. Thus, our comparative studies confirm conclusions from earlier works that the formulation of sea salt generation by Monahan et al. (1986) gives the soundest results for bubble-mediated sea spray. This justifies the selection of $M \& M$ for further use within EMEP model. 
Compared with multi-year measurements at the EMEP network, the EMEP model shows a tendency to overestimate $\mathrm{Na}^{+}$air concentrations, with bias improving from $46 \%$ in 2004 to $8 \%$ in 2007 as the number of measurement sites (in particular, in-land sites) more than doubles during that period. At the same time, $\mathrm{Na}^{+}$in precipitation (and wet deposition) is under-predicted, especially in the seasons outside summer and especially in winter. The EMEP model reproduces the geographical distribution of $\mathrm{Na}^{+}$in air and precipitation fairly well, with spatial correlation varying respectively between 0.76 and 0.81 and between 0.70 and 0.91 for the years 2004-2007. The model is also doing quite a good job at capturing sea salt episodes, as indicated by temporal correlation coefficients lying between 0.5 and 0.8 at most of the sites in the period 2004 to 2007.

Comparison with data from EMEP intensive measurement periods, during which $\mathrm{Na}^{+}$in $\mathrm{PM}_{10}$ and $\mathrm{PM}_{2.5}$ was determined at four sites in June 2006 and January 2007, suggests that the model may calculate too small production of sea salt mass, especially in the summer month. The results also indicate the possibility of too efficient removal of sea salt aerosol from the air, as calculated $\mathrm{Na}^{+}$air concentrations tend to be greater under-predicted at sites farther from the sea. Model calculated distribution of sea salt mass between fine and coarse aerosols is quite close to observed on average. However, for some sites, more $\mathrm{Na}^{+}$is allocates by the model to the fine fraction in summer compared to winter, which is not seen in the measurement data. This implies that further testing is needed to evaluate the soundness of $M$ \& $M$ parameterisation with respect to wind speed dependence of sea salt flux and size distribution of sea salt aerosol.

A series of sensitivity tests has been carried out to study the effects of the uncertainties in different parameters and processes on model results for sea salt. Calculated sea salt concetrations are shown to be sensitive to changing the meteorological driver, in particular due to changes in wind speed and precipitation data. Sea salt concentrations calculated with the EMEP model improve when using HIRLAM-v7.1 and ECMWF (IFS) meteorology compared to those using the older NWP model, PARLAM-PS.

Furthermore, some hypotheses have been tested regarding possible reasons for underestimation of $\mathrm{Na}^{+}$in precipitation by the EMEP model. In particular, uncertainties associated with calculations of sea salt generation and the efficiency of dry and wet removal have been analysed. Increasing in-cloud scavenging ratio by a factor of two or increasing below-cloud scavenging efficiency to $100 \%$ results in nearly unbiased calculated $\mathrm{Na}^{+}$in air, whereas the obtained increase in $\mathrm{Na}^{+}$in precipitation (and $\mathrm{Na}^{+}$wet deposition) is negligible. Furthermore, some moderation of model underestimation of $\mathrm{Na}^{+}$in precipitation is achieved by reducing dry deposition velocity by half, but $\mathrm{Na}^{+}$in air becomes far too high in this case.
Conjecturing that calculated sea salt fluxes are too low, we have also tested simultaneous enhancement of sea salt production and wet scavenging. These tests do not either eliminate underestimation of $\mathrm{Na}^{+}$in precipitation, while produce too high $\mathrm{Na}^{+}$air concentrations. The best results are obtained by increasing the emissions by $50 \%$ and assuming scavenging ratio as high as $2.6 \times 10^{6}$. Then $\mathrm{Na}^{+}$in precipitation is underestimated by about $40 \%$, while $\mathrm{Na}^{+}$in air is overestimated by about $25 \%$. In addition, these results tend to overestimate sea salt at coastal sites, whereas underestimate them at in-land sites, thus exaggerating sea salt regional gradients. Finally, accounting for the contribution of sea salt particles larger than $10 \mu \mathrm{m}$ (up to approximately $25-30 \mu \mathrm{m}$ ) renders only a rather small reduction of model underestimation of $\mathrm{Na}^{+}$in precipitation.

Concurrent examination of daily time-series for $\mathrm{Na}^{+}$in air and precipitation shows no clear pattern in the model performance on days with and without precipitation. Frequency distribution analysis shows that the model under-predicts the number of occurrences for the whole range of $\mathrm{Na}^{+}$wet deposition values, except from the smallest ones. This underprediction grows with increasing $\mathrm{Na}^{+}$wet deposition values, and the model does not at all reproduces observed cases with $\mathrm{Na}^{+}$wet depositions above $40-50 \mathrm{mg} \mathrm{m}^{-2}$. Model underestimations of sea salt in precipitation were also reported in Foltescu et al. (2004) and Guelle et al. (2001).

Another plausible explanation of the discrepancies in $\mathrm{Na}^{+}$ wet deposition discussed here could be that the model does not mix up sea salt high enough. That would lead to too fast removal of aerosols, too short lifetime scales, and thus too short transport distances. As a result, there could be not enough sea salt in the air over land in order to feed precipitating cloud. Model experiments, varying the efficiency of vertical mixing (including accounting for convective up-lift), would help to investigate this conjecture.

Besides modelling uncertainties, there are also uncertainties associated with measurements of $\mathrm{Na}^{+}$wet deposition. At coastal sites, the collecting vessel may be contaminated by dry deposited large sea salt particles during dry periods. Also, $\mathrm{Na}^{+}$wet deposition can be affected by local $\mathrm{NaCl}$ (not marine) sources and $\mathrm{Na}^{+}$from dust. For instance, in Guelle et al. (2001), measurements of $\mathrm{Na}^{+}$wet depositions were corrected for mineral dust to exclude non-sea salt contributions to measured $\mathrm{Na}^{+}$. More investigations are clearly needed to explain existing discrepancies between calculated and measured $\mathrm{Na}^{+}$wet deposition.

To test the robustness of our sea salt model results, sea salt calculations with the EMEP model have been compared with results from the SILAM model and observations for 2007. Both models are found to realistically reproduce the observed distribution of sea salt concentrations, with a spatial correlation between calculated and measured $\mathrm{Na}^{+}$of 0.73 for EMEP and 0.78 for SILAM. For about two thirds of the sites, the models calculate quite close values of $\mathrm{Na}^{+}$concentrations, whereas significant discrepancies are found at the 
Finnish and Irish stations, strongly influenced by sea spray. Both models somewhat underestimate $\mathrm{Na}^{+}$concentrations at about $70 \%$ of the sites, with the largest underestimation occurring at the coastal Irish site IE08. The temporal correlations between calculated and measured daily $\mathrm{Na}^{+}$air concentrations are quite variable for both models, and tend to be somewhat better at sites located at short and medium distances from the sea compared to in-land sites. Differences in calculated sea salt are explained to be mainly due to different parameterisations of sea spray, the use of different meteorological drivers and different grid resolutions used in model calculations, i.e. $50 \times 50 \mathrm{~km}^{2}$ for EMEP and $20 \times 20 \mathrm{~km}^{2}$ for SILAM. Summarising, the comparison between EMEP and SILAM performance shows the consistency of results (for most of measurement sites) and gives us additional confidence in the soundness of EMEP model sea salt calculations. Therefore, we conclude that the overall EMEP model accuracy for sea salt is not significantly degraded due to a relatively coarse model resolution and somewhat simpler sea salt description compared to the SILAM model.

This work is a part of overall EMEP model development. Improving sea salt modelling will facilitate improvement of nitrate chemistry in the EMEP model, namely formation of coarse nitrate associated with sea salt. Some work has already been done to include a kinetic parameterisation to describe the uptake of $\mathrm{HNO}_{3}$ on sea salt aerosols and its further reaction with $\mathrm{NaCl}$ to form coarse $\mathrm{NaNO}_{3}$ particles (Berge, 2009). First results show improvements in correlation between calculated and observed nitrate for several EMEP stations, which is very promising. In broader perspective, providing better insight on the model's ability to reproduce sea salt concentrations and assessing the uncertainties associated with sea salt calculations, this work contributes to further improvement of aerosol modelling on both regional and global scales.

\section{Appendix A}

Table A1. EMEP sites (http://tarantula.nilu.no/projects/ccc/ sitedescriptions/index.html).

\begin{tabular}{lllrr}
\hline Country & Site code & Site name & Lat & Lon \\
Austria & AT02 & Illmitz & $47^{\circ} 46^{\prime} \mathrm{N}$ & $16^{\circ} 46^{\prime} \mathrm{E}$ \\
\hline Germany & DE01 & Westerland & $54^{\circ} 56^{\prime} \mathrm{N}$ & $08^{\circ} 19^{\prime} \mathrm{E}$ \\
& DE02 & Langenbruegge & $52^{\circ} 48^{\prime} \mathrm{N}$ & $10^{\circ} 45^{\prime} \mathrm{E}$ \\
& DE03 & Schauinsland & $47^{\circ} 55^{\prime} \mathrm{N}$ & $07^{\circ} 54^{\prime} \mathrm{E}$ \\
& DE07 & Neuglobsow & $53^{\circ} 09^{\prime} \mathrm{N}$ & $13^{\circ} 02^{\prime} \mathrm{E}$ \\
& DE09 & Zingst & $54^{\circ} 26^{\prime} \mathrm{N}$ & $12^{\circ} 44^{\prime} \mathrm{E}$ \\
& DE44 & Melpitz & $51^{\circ} 32^{\prime} \mathrm{N}$ & $12^{\circ} 56^{\prime} \mathrm{E}$ \\
\hline \multirow{2}{*}{ Denmark } & DK03 & Tange & $56^{\circ} 21^{\prime} \mathrm{N}$ & $9^{\circ} 36^{\prime} \mathrm{E}$ \\
& DK05 & Keldsnor & $54^{\circ} 44^{\prime} \mathrm{N}$ & $10^{\circ} 44^{\prime} \mathrm{E}$ \\
& DK08 & Anholt & $56^{\circ} 43^{\prime} \mathrm{N}$ & $11^{\circ} 31^{\prime} \mathrm{E}$ \\
& DK31 & Ulborg & $56^{\circ} 17^{\prime} \mathrm{N}$ & $8^{\circ} 26^{\prime} \mathrm{E}$ \\
\hline Finland & FI09 & Utö & $59^{\circ} 47^{\prime} \mathrm{N}$ & $21^{\circ} 23^{\prime} \mathrm{E}$ \\
& FI17 & Virolahti & $60^{\circ} 31^{\prime} \mathrm{N}$ & $27^{\circ} 41^{\prime} \mathrm{E}$ \\
& FI36 & Pallas & $68^{\circ} 00^{\prime} \mathrm{N}$ & $24^{\circ} 15^{\prime} \mathrm{E}$ \\
\hline Ireland & IE01 & Valentia Obs. & $51^{\circ} 56^{\prime} \mathrm{N}$ & $10^{\circ} 15^{\prime} \mathrm{W}$ \\
& IE05 & Oak Park & $52^{\circ} 52^{\prime} \mathrm{N}$ & $6^{\circ} 55^{\prime} \mathrm{W}$ \\
& IE06 & Malin Head & $55^{\circ} 23^{\prime} \mathrm{N}$ & $7^{\circ} 20^{\prime} \mathrm{W}$ \\
& IE08 & Carnsore Point & $52^{\circ} 11^{\prime} \mathrm{N}$ & $6^{\circ} 22^{\prime} \mathrm{W}$ \\
\hline Iceland & IS02 & Irafoss & $64^{\circ} 05^{\prime} \mathrm{N}$ & $21^{\circ} 01^{\prime} \mathrm{W}$ \\
\hline Norway & NO01 & Birkenes & $58^{\circ} 23^{\prime} \mathrm{N}$ & $8^{\circ} 15^{\prime} \mathrm{E}$ \\
& NO15 & Tustervatn & $65^{\circ} 50^{\prime} \mathrm{N}$ & $13^{\circ} 55^{\prime} \mathrm{E}$ \\
& NO39 & Kaarvatn & $62^{\circ} 47^{\prime} \mathrm{N}$ & $8^{\circ} 53^{\prime} \mathrm{E}$ \\
& NO42 & Zeppelin & $78^{\circ} 54^{\prime} \mathrm{N}$ & $11^{\circ} 53^{\prime} \mathrm{E}$ \\
& NO55 & Karasjok & $69^{\circ} 28^{\prime} \mathrm{N}$ & $25^{\circ} 13^{\prime} \mathrm{E}$ \\
\hline & SI08 & Iskrba & $45^{\circ} 34^{\prime} \mathrm{N}$ & $14^{\circ} 52^{\prime} \mathrm{E}$ \\
\hline SK0vakia & Stara Lesna & $49^{\circ} 09^{\prime} \mathrm{N}$ & $20^{\circ} 17^{\prime} \mathrm{E}$ \\
& SK06 & Starina & $49^{\circ} 03^{\prime} \mathrm{N}$ & $22^{\circ} 16^{\prime} \mathrm{E}$ \\
\hline
\end{tabular}


Table A2. Model bias (\%) and correlation for daily $\mathrm{Na}^{+}$concentrations in air for 2006 compared to observations at EMEP sites. Here, observed (Obs) $\mathrm{Na}^{+}$concentrations are in $\mu \mathrm{g} \mathrm{m}^{-3}$, Bias is in $\%$.

\begin{tabular}{|c|c|c|c|c|c|c|c|c|c|c|c|}
\hline & \multirow[t]{2}{*}{ Obs } & \multicolumn{2}{|c|}{$M \& M$} & \multicolumn{2}{|c|}{ G03 } & \multicolumn{2}{|c|}{ A98 } & \multicolumn{2}{|c|}{ SH98 } & \multicolumn{2}{|c|}{ V01 } \\
\hline & & Bias & $R$ & Bias & $R$ & Bias & $R$ & Bias & $R$ & Bias & $R$ \\
\hline AT02 & 0.10 & -41 & 0.03 & -41 & 0.04 & -73 & 0.02 & -79 & 0.04 & -10 & -0.01 \\
\hline DE01 & 1.56 & 0 & 0.81 & 18 & 0.81 & -13 & 0.52 & -42 & 0.81 & 109 & 0.34 \\
\hline DE02 & 0.39 & -30 & 0.64 & -25 & 0.63 & -60 & 0.42 & -70 & 0.63 & 15 & 0.34 \\
\hline DE03 & 0.14 & -40 & 0.53 & -42 & 0.50 & -78 & 0.44 & -80 & 0.49 & -27 & 0.38 \\
\hline DE07 & 0.37 & -41 & 0.63 & -38 & 0.60 & -66 & 0.38 & -76 & 0.58 & 1 & 0.33 \\
\hline DE09 & 0.57 & 9 & 0.74 & 25 & 0.73 & 14 & 0.38 & -42 & 0.73 & 200 & 0.26 \\
\hline DK03 & 0.97 & -26 & 0.79 & -16 & 0.79 & -42 & 0.51 & -62 & 0.79 & 50 & 0.33 \\
\hline DK05 & 1.10 & 1 & 0.72 & 18 & 0.71 & 16 & 0.29 & -43 & 0.72 & 198 & 0.02 \\
\hline DK08 & 1.52 & -1 & 0.81 & 16 & 0.80 & 26 & 0.35 & -43 & 0.80 & 229 & -0.12 \\
\hline DK31 & 1.31 & -7 & 0.83 & 8 & 0.83 & -24 & 0.57 & -49 & 0.83 & 87 & 0.39 \\
\hline IE01 & 2.06 & 64 & 0.56 & 91 & 0.58 & 30 & 0.14 & -5 & 0.58 & 202 & -0.09 \\
\hline IE05 & 1.00 & 5 & 0.59 & 17 & 0.59 & -30 & 0.19 & -47 & 0.60 & 76 & -0.01 \\
\hline IE06 & 2.44 & 17 & 0.69 & 38 & 0.70 & -11 & 0.39 & -31 & 0.71 & 101 & 0.13 \\
\hline IE08 & 3.66 & -51 & 0.65 & -44 & 0.65 & -60 & 0.32 & -73 & 0.66 & -1 & 0.12 \\
\hline IS02 & 1.00 & 72 & 0.56 & 109 & 0.57 & 21 & 0.24 & 3 & 0.57 & 173 & 0.09 \\
\hline NO01 & 0.44 & -10 & 0.64 & -1 & 0.62 & -39 & 0.31 & -59 & 0.60 & 70 & 0.21 \\
\hline NO15 & 0.25 & 98 & 0.54 & 140 & 0.54 & 45 & 0.39 & 16 & 0.54 & 239 & 0.32 \\
\hline NO39 & 0.16 & 109 & 0.56 & 151 & 0.55 & 46 & 0.45 & 21 & 0.55 & 240 & 0.41 \\
\hline $\mathrm{NO} 42$ & 0.25 & 450 & 0.40 & 597 & 0.41 & 464 & 0.05 & 252 & 0.41 & 1282 & -0.08 \\
\hline NO55 & 0.23 & 37 & 0.58 & 67 & 0.59 & -3 & 0.38 & -25 & 0.59 & 147 & 0.29 \\
\hline SI08 & 0.14 & -44 & 0.4 & -46 & 0.37 & -38 & 0.33 & -80 & 0.37 & 110 & 0.3 \\
\hline SK04 & 0.19 & -71 & 0.08 & -70 & 0.06 & -86 & 0.09 & -89 & 0.04 & -54 & 0.12 \\
\hline Mean & 0.90 & 23 & 0.58 & 44 & 0.58 & 2 & 0.33 & -32 & 0.57 & 156 & 0.19 \\
\hline
\end{tabular}

Table A3. Statistical analysis of $\mathrm{Na}^{+}$air concentrations calculated with the EMEP and the SILAM models against measurements in 2007. Here, observed (Obs) $\mathrm{Na}^{+}$concentrations are in $\mu \mathrm{g} \mathrm{m}^{-3}$, Bias is in $\%$.

\begin{tabular}{|c|c|c|c|c|c|c|c|c|c|}
\hline & \multirow[b]{2}{*}{ Obs } & \multicolumn{4}{|c|}{ EMEP } & \multicolumn{4}{|c|}{ SILAM } \\
\hline & & Mod & Bias & $R$ & RMSE & Mod & Bias & $R$ & RMSE \\
\hline AT02 & 0.09 & 0.07 & -32 & 0.54 & 0.08 & 0.07 & -27 & 0.60 & 0.08 \\
\hline DE01 & 2.54 & 1.89 & -35 & 0.55 & 3.06 & 2.80 & 10 & 0.56 & 2.92 \\
\hline DE02 & 0.53 & 0.4 & -35 & 0.57 & 0.54 & 0.33 & -37 & 0.72 & 0.47 \\
\hline DE03 & 0.17 & 0.1 & -45 & 0.42 & 0.25 & 0.13 & -24 & 0.44 & 0.26 \\
\hline DE07 & 0.48 & 0.3 & -46 & 0.56 & 0.62 & 0.28 & -41 & 0.68 & 0.56 \\
\hline DE09 & 0.94 & 0.89 & -17 & 0.67 & 0.70 & 0.62 & -34 & 0.82 & 0.63 \\
\hline DK03 & 1.28 & 0.94 & -36 & 0.58 & 1.20 & 0.99 & -23 & 0.54 & 1.18 \\
\hline DK05 & 1.35 & 1.78 & 16 & 0.8 & 0.86 & 1.36 & 1 & 0.72 & 0.73 \\
\hline DK08 & 1.92 & 2.03 & -8 & 0.82 & 0.86 & 2.09 & 9 & 0.73 & 1.06 \\
\hline DK31 & 1.71 & 1.58 & -19 & 0.82 & 0.88 & 1.68 & -2 & 0.83 & 0.85 \\
\hline FI09 & 0.38 & 2.59 & 498 & 0.74 & 2.38 & 0.50 & 31 & 0.62 & 0.33 \\
\hline FI17 & 0.2 & 0.51 & 128 & 0.73 & 0.41 & 0.11 & -45 & 0.58 & 0.17 \\
\hline FI36 & 0.17 & 0.14 & -30 & 0.43 & 0.22 & 0.13 & -24 & 0.44 & 0.21 \\
\hline IE01 & 2.47 & 3.07 & 9 & 0.68 & 1.92 & 2.31 & -7 & 0.69 & 1.91 \\
\hline IE05 & 0.89 & 0.89 & -12 & 0.54 & 0.69 & 0.68 & -24 & 0.66 & 0.60 \\
\hline IE06 & 2.43 & 3.13 & 13 & 0.65 & 1.73 & 1.91 & -22 & 0.68 & 1.55 \\
\hline IE08 & 3.51 & 1.51 & -63 & 0.79 & 3.25 & 1.36 & -61 & 0.77 & 3.27 \\
\hline ISO2 & 0.95 & 1.28 & 18 & 0.54 & 1.07 & & & & \\
\hline NO01 & 0.35 & 0.32 & -21 & 0.59 & 0.39 & 0.51 & 45 & 0.73 & 0.38 \\
\hline NO15 & 0.29 & 0.59 & 74 & 0.45 & 0.62 & 0.54 & 85 & 0.63 & 0.51 \\
\hline NO39 & 0.17 & 0.49 & 158 & 0.41 & 0.58 & 0.33 & 94 & 0.37 & 0.39 \\
\hline $\mathrm{NO} 42$ & 0.23 & 0.59 & 123 & 0.31 & 0.64 & & & & \\
\hline NO55 & 0.22 & 0.25 & 0 & 0.47 & 0.28 & 0.28 & 26 & 0.56 & 0.30 \\
\hline SI08 & 0.11 & 0.08 & -39 & 0.47 & 0.15 & 0.09 & -21 & 0.75 & 0.11 \\
\hline SK04 & 0.09 & 0.05 & -49 & 0.52 & 0.08 & 0.06 & -29 & 0.42 & 0.11 \\
\hline SK06 & 0.08 & 0.07 & -20 & 0.53 & 0.08 & 0.07 & -16 & 0.50 & 0.10 \\
\hline
\end{tabular}


Acknowledgements. The authors are grateful to Perrino S. at C. N. R. Institute of Atmospheric Pollution and Makkonen U. at the Finnish Meteorological Institute for intensive measurement data used in this work.

Edited by: H. C. Hansson

\section{References}

Andreas, E. L.: A new sea spray generation function for wind speeds up to $32 \mathrm{~m} \mathrm{~s}^{-1}$, J. Phys. Oceanogr., 28, 2175-2184, 1998.

Andreas, E. L., Pattison, M. J., and Belcher, S. E.: Production rates of sea-spray droplets, in: Clarification and elaboration, edited by: Pattison, M. J. and Belcher, S. E., J. Geophys. Res., 106, C4, 7157-7161, 2001.

Athanasopoulou, E., Tombrou, M., Pandis, S. N., and Russell, A. G.: The role of sea-salt emissions and heterogeneous chemistry in the air quality of polluted coastal areas, Atmos. Chem. Phys., 8, 5755-5769, doi:10.5194/acp-8-5755-2008, 2008.

Berge, H.: Implementation and evaluation of a parameterisation of coarse nitrate, Master Thesis in Geoscience, Meteorology and Oceanography, University of Oslo, Department of Geoscience, Oslo, Norway, 2009.

Blomqvist, G. and Johansson, E.-L.: Airborne spreading and deposition of de-icing salt - a case study, The Science of The Total Environment, 235, 161-168, 1999.

Clarke, A. D., Owens, S. R., and Zhou, J.: An ultrafine sea-salt flux from breaking waves: Implications for cloud condensation nuclei in the remote marine atmosphere, J. Geophys. Res., 111, D06202, doi:10.1029/2005JD006565, 2006.

de Leeuw, G., Neele, F. P., Hill, M., Smith, M. H., and Vignati, E.: Production of sea spray aerosol in the surf zone, J. Geophys. Res., 105, 29397-29409, 2000.

EC DIRECTIVE 2008/50/EC of the european parliament and of the council of 21 May 2008 on ambient air quality and cleaner air for Europe: http://ec.europa.eu/environment/air/legis.htm, 2008

EMEP/CCC: Manual for sampling and chemical analysis, Revised November 2001. Norwegian Institute for Air Research Kjeller, EMEP/CCC-Report 1/95, URL: http://tarantula.nilu.no/projects/ ccc/manual/index.html, 1995.

Fagerli, H., Simpson, D., and Tsyro, S.: Unified EMEP model: Updates, in Transboundary acidification, eutrophication and ground level ozone in Europe. EMEP Status Report 1/2004, 11-18, Norwegian Meteorological Institute, Oslo, Norway, 2004.

Foltescu, V. L., Pryor, S. C., and Bennet, C.: Sea salt generation and removal on the regional scale, Atmos. Environ., 39, 2123-2133, 2004.

Garratt, J. R.: The atmospheric boundary layer. Cambridge University Press, 1992.

Geever, M., O'Dowd, C. D., van Ekeren, S., Flanagan, R., Nilsson, E. D., de Leeuw, G., and Rannik, U.: Submicron sea spray fluxes, Geophys. Res. Lett., 32, L15810, doi:10.1012/2005GL023081, 2005.

Gerber, H. E.: Relative-humidity parameterisation of the Navy aerosol model (NAM), NRL Rep. 8956, Natl., Res. Lab., Washington DC, USA, 1985.

Grini, A., Myhre, G., Sundet, J. K. and Isaksen, I. S. A.: Modelling the annual cycle of sea salt in the global 3-D model OSLO
CTM-2, Concentrations, fluxes, and radiative impact, J. Clim., 15, 1717-1730, 2002.

Gong, S. L.: A parameterisation of sea-salt aerosol source function for sub- and super-micron particles, Global Biogeochem. Cy., 17, 1097, doi:10.1029/2003GB002079, 2003.

Gong, S. L., Barrie, L. A., and Blanchet, J.-P.: Modeling sea-salt aerosols in the atmosphere: 1, Model development, J. Geophys. Res., 102, 3805-3818, 1997a.

Gong, S. L., Barrie, L. A., Prospero, J. M., Savoie, D. L., Ayers, G. P., Blanchet, J.-P., and Spacek, L.: Modeling sea-salt aerosols in the atmosphere: 2. Atmospheric concentrations and fluxes, J. Geophys. Res., 102, 3819-3830, 1997 b.

Gong, S. L., Barrie, L. A., and Lazare, M.: Canadian Aerosol Module(CAM): A size-segregated simulation of atmospheric aerosol processes for climate and air quality models, 2. Global sea-salt aerosol and its budgets, J. Geophys. Res., 107, 4779, doi:10.1029/2001GB002004, 2002.

Guelle, W., Schulz, M., Balkanski, Y., and Dentener, F.: Influence of the source formulation on modeling atmospheric global distribution of sea salt aerosol, J. Geophys. Res., 106, 27509-27524, 2001.

Hellsten, S., van Loon, M., Tarrason, L., Vestreng, V., Tørseth, K., Kindbom, K., and Aas, W.: Base cations deposition in Europe, IVL Report B1722, Swedish Environmental Research Institute, Stockholm, http://www3.ivl.se/rapporter/pdf/B1722.pdf, 2007.

Hoppel, W. A., Frick, G. M., and Fitzgerald, J. W.: Surface source function for sea-salt aerosol and aerosol dry deposition to the ocean surface, J. Geophys. Res., 107, 4382, doi:10.1029/2001JD002014, 2002.

Hjellbrekke, A.-G. and Fjæraa, A. M.: Data Report 2007 Acidifying and eutrophying compounds and particulate matter, EMEP/CCCReport 1/2009, Norwegian Institute for Air Research, Kjeller, 2009.

Langmann, B., Varghese, S., Marmer, E., Vignati, E., Wilson, J., Stier, P., and O'Dowd, C.: Aerosol distribution over Europe: a model evaluation study with detailed aerosol microphysics, Atmos. Chem. Phys., 8, 1591-1607, doi:10.5194/acp-8-1591-2008, 2008.

Lewis, E. R. and Schwartz, S. E.: Sea Salt Aerosol Production: Mechanisms, Methods, Measurements, and Models: A Critical Review, American Geophysical Union, Washington, DC, USA, 2004.

Liu, H., Crawford, J. H., Pierce, R. B., Norris, P., Yantosca, R. M., Evans, M. J., Kittaka, C., Feng, J., and Tie, X: Radiative effect of clouds on tropospheric chemistry in a global threedimensional chemical transport model, J. Geophys. Res., 111, D20303, doi:10.1029/2005JD006403, 2006.

Ma, X., von Salzen, K., and Li, J.: Modelling sea salt aerosol and its direct and indirect effects on climate, Atmos. Chem. Phys., 8, 1311-1327, doi:10.5194/acp-8-1311-2008, 2008.

Maykut, N., Lewtas, J., Kim, E. and Larson, T. V.: Source apportionment of $\mathrm{PM}_{2.5}$ at an urban IMPROVE site in Seattle, Washington, Envir. Sci. Tech., 37, 5135-5142, 2003.

Millero, F. J.: Physicochemical controls on seawater, in: Treatise on Geochemistry, edited by: Holland, H. D. and Turkian, K. K., Elsevier, Amsterdam, The Netherlands, 2004.

Monahan E. C. and O'Muircheartaigh, I.: Optimal power-law description of oceanic whitecap coverage dependence on wind speed, J. Phys. Oceanogr., 10, 2094-2099, 1980. 
Monahan, E. G., Spiel, D. E., and Davidson, K. L.: A model of marine aerosol generation via whitecaps and wave disruption, in Oceanic Whitecaps, edited by: Monahan, E. and Niocaill, G. M., 167-174, D. Reidel, Norwell, Mass., 1986.

Mårtensson, E. M., Tunved, P. Korhonen, H., and Nilsson, E. D.: Are submicrometer sea salt emission parameterisations consistent with observed remote marine aerosol distributions?, in: Submicrometre aerosol emissions from sea spray and road traffic, Doctoral Thesis in Atmospheric Science, Stockholm University, Sweden, 2007.

Mårtensson, E. M., Nilsson, E. D., de Leeuw, G., Cohen, L. H., and Hansson, H.-C.: Laboratory simulations and parameterisation of the primary marine aerosol production, J. Geophys. Res., 108, p. 4297, doi:10.1029/2002JD002263, 2003.

Nilsson, E. D., Mårtensson, E. M., Van Ekeren, J. S., de Leeuw, G., Moerman, M., and O’Dowd, C.: Primary marine aerosol emissions: size resolved eddy covariance measurements with estimates of the sea salt and organic carbon fractions, Atmos. Chem. Phys. Discuss., 7, 13345-13400, doi:10.5194/acpd-713345-2007, 2007.

O'Dowd, C. D., Smith, M. H., Costerdine, I. E., and Lowe, J. A.: Marine aerosol, sea salt, and the marine sulphur cycle: A short review, Atmos. Environ., 32, 73-80, 1997.

Ooki, A., Uematsu, M., Miura, K., and Nakae, S.: Sources of sodium in atmospheric fine particles, Atmos. Environ., 36, 43674374, 2002.

Pierce, J. and Adams, P. J.: Global evaluation of $\mathrm{CCN}$ formation by direct emission of sea salt and growth of ultrafine sea salt, J. Geophys. Res., 111, D06203, doi:10.1029/2005JD006186, 2006.

Pryor, S. C., Barthelmie, R, J., Schoof, J. T., Binkowski, F. S., Delle Monache, L., and Stull, R.: Modeling the impact of sea-spray on particle concentrations in a coastal city, Sci. Total Environ., 391, 132-142, 2007.

Schulz, M., de Leeuw, G., and Balkanski, Y.: Sea salt aerosol source functions and emissions, in: Emissions of Atmospheric Trace Components, edited by: Granier, C., Artaxo, P., and Reeves, C., 333-359, Kluwer Academic Publishers, Dordrecht, The Netherlands, 2004.

Sellegri, K., Gourdeau, J., Putaud, J. P. and Despiau, S.: Chemical composition of marine aerosol in a Mediterranean coastal zone during the FETCH experiment, J. Geophys. Res., 106, 1202312037, 2001.

Simpson, D., Fagerli, H., Jonson, J. E., Tsyro, S., Wind, P., and Tuovinen, J.-P.: Transboundary Acidification, Eutrophication and Ground Level Ozone in Europe, Part I. Unified EMEP Model Description, EMEP/MSC-W Status report 1/2003 Part I, Norwegian Meteorological Institute, Oslo, Norway, http://www.emep. int., 2003,
Smith, M. H. and Harrison, N. M.: The sea spray generation function, J. Aerosol Sci., 29, 189-190, 1998.

Smith, M. H., Park, P. M., and Consterdine, I. E.: Marine aerosol concentrations and estimated fluxes over sea, Q. J. R. Meteorol Soc., 119, 809-824, 1993.

Sofiev M., Siljamo, P., Valkama, I., Ilvonen, M., and Kukkonen, J.: A dispersion modelling system SILAM and its evaluation against ETEX data, Atmos. Environ., 40, 674-685, DOI:10.1016/j.atmosenv.2005.09.069, 2006.

Sofiev, M., Soares, J. Prank, M. de Leeuw, G., and Kukkonen, J.: A regional-to-global model of emission and transport of sea salt particles in the atmosphere, in press, 2011.

Stier, P., Feichter, J., Kinne, S., Kloster, S., Vignati, E., Wilson, J., Ganzeveld, L., Tegen, I., Werner, M., Balkanski, Y., Schulz, M., Boucher, O., Minikin, A., and Petzold, A.: The aerosolclimate model ECHAM5-HAM, Atmos. Chem. Phys., 5, 11251156, doi:10.5194/acp-5-1125-2005, 2005.

Stull, R. B.: An Introduction to Boundary Layer Meteorology, Atmospheric Science Library, Kluwer Academic Publishers, 1988.

Tsyro, S.: Regional Model for Formation, Dynamics, and Longrange Transport of Atmospheric Aerosol. Russian Meteorology and Hydrology, ISSN 1068-3739, 33, 2, 82-90, 2008.

Tsyro, S., Berge, H., Benedictow, A., and Gauss, M.: Studying the effect of meteorological input on Unified EMEP model results. In: Transboundary acidification, eutrophication and ground level ozone in Europe in 2008, EMEP Status Report 1/2010, Norwegian Meteorological Institute, Oslo, Norway, http://www.emep. int., 2010,

van Loon, M., Tarrasón, L. and Posch, M.: Modelling Base Cations in Europe, MSC-W Technical Report 2/05, Norwegian Meteorological Institute, Oslo, Norway, 2005.

Uggerud, H. and Hjellbrekke, A.-G.: The twenty-sixth intercomparison of analytical methods within EMEP, Norwegian Institute for Air Research, Kjeller, EMEP/CCC-Report 6/2009, 2009.

van den Berg, A., Dentener, F., and Lelieveld, J.: Modeling the chemistry of the marine boundary layer: Sulphate formation and the role of sea-salt aerosol particles, J. Geophys. Res., 105, 11,671-11,698, doi:10.1029/1999JD901073, 2000.

Vignati, E., de Leeuw, G., and Berkowicz, R.: Modeling coastal aerosol transport and effects of surf-produced aerosols on process in the marine atmospheric boundary layer, J. Geophys. Res., 105, D17, 20,225-20,238, 2001.

White, W. H.: Chemical markers for sea salt in IMPROVE aerosol data, Atmos. Environ., 42, 261-274, 2008.

Zakey, A. S., Giorgi, F., and Bi, X.: Modelling of se salt in a regional climate model: Fluxes and radiative forcing, J. Geophys. Res., 113, D14221, doi:10.1029/2007JD009209, 2008. 